\title{
Characterisation of rock aggregate breakage properties using realistic texture-based modelling
}

\author{
Hongyuan $\mathrm{Liu}^{1, *, \dagger}{ }^{1,}$ Per-Arne Lindqvist ${ }^{2}$, Urban $\AA^{k}$ kesson ${ }^{3}$, Shaoquan $\mathrm{Kou}^{4}$ \\ and Jan-Eric Lindqvist ${ }^{3}$ \\ ${ }^{1}$ School of Engineering, University of Tasmania, Hobart TAS7001, Australia \\ ${ }^{2}$ Department of Applied Chemistry and Geoscience, Luleå University of Technology, Luleå 97187, Sweden \\ ${ }^{3}$ CBI Swedish Cement and Concrete Institute, Borås, 50115, Sweden \\ ${ }^{4}$ Institute of Mechanics, Chinese Academy of Sciences, Beijing 100190, China
}

\begin{abstract}
SUMMARY
Realistic texture-based modelling methods, that is microstructural modelling and micromechanical modelling, are developed to simulate the rock aggregate breakage properties on the basis of the rock actual microstructure obtained using microscopic observations and image analysis. The breakage properties of three types of rocks, that is Avja, LEP and Vandle taken from three quarries in Sweden, in single aggregate breakage tests and in inter-aggregate breakage tests are then modelled using the proposed methods. The microstructural modelling directly integrates the microscopic observation, image analysis and numerical simulation together and provides a valuable tool to investigate the mechanical properties of rock aggregates on the basis of their microstructure properties. The micromechanical modelling takes the most important microstructure properties of rock aggregates into consideration and can model the major mechanical properties. Throughout this study, it is concluded that in general, the microstructure properties of rock aggregate work together to affect their mechanical properties, and it is difficult to correlate a single microstructure property with the mechanical properties of rock aggregates. In particular, for the three types of rock Avja, LEP and Vandle in this study, crack size distribution, grain size and grain perimeter (i.e. grain shape and spatial arrangement) show good correlations with the mechanical properties. The crack length and the grain size negatively affect the mechanical properties of Avja, LEP and Vandle, but the perimeter positively influences the mechanical properties. Besides, the modelled rock aggregate breakage properties in both single aggregate and inter-aggregate tests reveal that the aggregate microstructure, aggregate shape and loading conditions influence the breakage process of rock aggregate in service. For the rock aggregate with the same microstructure, the quadratic shape and good packing dramatically improve its mechanical properties. During services, the aggregate is easiest to be fragmented under point-to-point loading condition, and then in the sequence of multiple-point, point-to-plane and plane-to-plane loading conditions. Copyright (C) 2011 John Wiley \& Sons, Ltd.
\end{abstract}

Received 2 March 2010; Revised 12 January 2011; Accepted 13 April 2011

KEY WORDS: microstructural modelling; micromechanical modelling; microscopic observation; image analysis; rock breakage; rock aggregate

\section{INTRODUCTION}

Rock aggregates are used for road and railway construction, for the manufacture of asphalt and concrete, and for many other purposes. Thus, the availability of high quality, low cost and environmentally friendly rock aggregates and their recirculation are important for the development of a sustainable society. In recent years, because of the increasing expansions of constructions and the

\footnotetext{
*Correspondence to: Hongyuan Liu, School of Engineering, University of Tasmania, Hobart TAS7001, Australia.

†E-mail: Hong.Liu@utas.edu.au
} 
introduction of strict laws on using natural aggregate resources throughout the world, the relative amount of crushed bedrock for producing rock aggregate has been steadily increasing.

Traditionally, the selection of rock aggregate is based on three main criteria [1]: (i) experience; (ii) reputation; and (iii) mechanical test. With the development of quantitative microscopy and image analysis, more and more researchers [2-6] realize that the rock microstructure plays an important role in rock aggregate breakage and have therefore been trying to predict the rock aggregate breakage properties by investigating the relationship between the microstructural and the mechanical properties. In most of the studies, the relationship is obtained from two separate processes: on the one hand, the microstructural properties of rock aggregates are quantified through microscopic method and image analyses; on the other hand, the mechanical properties are evaluated by laboratory mechanical tests. The two separate processes are then correlated using statistical single-variable or multiple-variable regression analyses. Therefore, most of the studies investigate the relationship between the microstructural and the mechanical properties of rock aggregates in an indirect way instead of directly explaining the physical mechanisms. Moreover, most of the studies only correlate the mechanical properties of rock aggregates with a single microstructural property, such as mineral composition, grain size, crack and others, which may be the reason why there are usually contradicted results in literatures predicted by different researchers.

Recently, with the rapid development of computing power, interactive computer graphics and topological data structure, numerical modelling has become a powerful technique to investigate the relationship from the mechanics point of view and take some of microstructural properties into considerations. In many numerical models, the microstructures of rock materials have been simply simulated through statistical methods [7-13]. Although the artificial microstructure generated by these statistical models can represent many key attributes of the rock breakage, it remains unclear to what extent the artificial microstructure can be justified on rock actual microstructure and how quantitative results from microscopy observations and image analyses can be used. These artificial microstructures are prevailing in rock mechanics because there had been lack of tools or methods to quantitatively establish the actual rock microstructure. More recently, Chen et al. [14] used digital image processing techniques to acquire the internal structures of different mineral distribution from colour rock image and incorporate them into the commercial numerical software FLAC to model rock breakage in Brazilian tests. Zhu et al. [15] implemented the same method as Chen et al.'s to incorporate the microstructure into a numerical model on the basis of the HSI (hue, saturation and intensity) colour space of a digital image. However, their so-called digital image processing technique introduces rock microstructure still in an artificial way because the parameters in their model are specified based on artificial specification of reasonable values according to the pixel colour. The authors [16] incorporated mineralogical heterogeneity into a numerical model to investigate the effect of minerals such as quartz, feldspar and biotite on the strength and deformation characteristics of rock. This study is the extension of the authors' previous work [16] and will incorporate the real microstructure obtained through quantitative microscopy and image analysis to model the rock aggregate breakage properties.

The main objective of this paper is to present a realistic texture-based modelling method for characterising the rock aggregate breakage properties according to its actual microstructure using integrated microscopic observation, image analysis and numerical modelling. More specifically, rock samples are firstly collected from several quarries of rock aggregate production. The microstructure of the rock samples is then characterised using quantitative microscopy and image analysis techniques. Thirdly, microstructural modelling and micromechanical modelling methods are developed for incorporating the actual microstructure into the numerical modelling. Finally, the breakage properties of rock aggregate in various loading conditions are predicted using either microstructural modelling or micromechanical modelling.

\section{CHARACTERISATION OF ROCK AGGREGATE MICROSTRUCTURE USING QUANTITATIVE MICROSCOPY AND IMAGE ANALYSIS}

Three granites are taken from three quarries for rock aggregate production in Sweden. Two of the rocks, which are named as LEP and Vandle, respectively, in this study are younger Stockholm granites 
sampled in the Stockholm and Västerås areas. The third sampled rock type is a Bohus granite from west Sweden, which is named as Avja. Cores with a diameter of $40 \mathrm{~mm}$ are drilled for each type of rock, and these cores are then used for microscopic observations and subsequent mechanical tests presented in Section 3. The microscopic observations and image analyses are conducted following the method developed by Åkesson [17].

Thin sections are cut from samples oriented parallel and perpendicular to the drill-core axis and then vacuum impregnated with an epoxy resin containing fluorescent dye. The thin section is fixed on a motorised stage programmed so the images are photographed edge-to-edge creating a 12-image mosaic. The thin section is then observed using optical microscopy with fluorescent light and polarised light, and correspondingly two 12-image pictures are obtained for each sample. The area of each picture is $3.977 \times 3.997 \mathrm{~mm}$, and the resolution is $2304 \times 2320$ pixels. For each rock type, three to four thin sections are observed, and thus up to an area of $128 \mathrm{~mm}^{2}$ are analysed. The fluorescent and polarised images were finally combined together as a basis for quantifying the microstructure. Figure 1(a) shows an example of the combined mosaic images of Avja, LEP and Vandle.

The mineral compositions of the rocks are obtained using the point count analysis on microscopic image. Grain size is obtained through drawing randomly draw transverse on microscopic image and then measuring the maximum ferret diameter on each mineral cutting a traverse. In order to identify different types of cracks, the combined images are printed with a size of $272 \times 269 \mathrm{~mm}$ and by using transparent paper, each crack type was traced and coloured (black, intra-granular; green, grainboundary; and red, trans-granular). The line drawings were scanned into the computer, and by using RGB-threshold technique, the number and length of the different crack types could be measured separately.

\section{NUMERICAL METHOD FOR MODELLING ROCK AGGREGATE BREAKAGE}

Formation and unstable growth of microcracks caused by the material inhomogeneities and external force is considered to be the mechanism of brittle failure [18] in rock breakage. The modelling of crack initiation, nucleation, propagation and interaction has been one of the greatest challenges in material failure analysis. Finite element method (FEM) is a widely used tool in engineering analysis because failure induces geometrical discontinuity in the medium. Traditionally, the effects of discontinuities have been modelled in FEM using higher-order shape functions or enrichment functions such as joint elements. However, this method can usually model single discontinuities with simple geometry and is not suitable for modelling discontinuities in the fracture of heterogeneous materials such as rock because there are a large number of cracks during fracture. On the other hand, classical continuum mechanics based approaches such as damage mechanics can be implemented into FEM without element-level modifications. At this moment, no commercial finite element software provides proper tools for brittle failure in heterogeneous rock. In this study, the RFPA-RT code, which is the rock and tool interaction code [19] developed by the authors on the basis of the realistic failure process analysis model [7], the FEM and continuum damage mechanics (CDM), will be used in this study to model rock breakage.

The concepts used in the RFPA-RT code for modelling discontinuities caused by material failure are based on CDM. In CDM, material damaging reduces the elastic stiffness because of breaking of atomic bonds or debonding caused by crack initiation, which is different from the theory of plasticity, where inelastic deformation induces irreversible strains caused by dislocation movement. Thus, in the RFPA-RT code, loss of stiffness can be considered to be a consequence of randomly distributed microcracks and can be macroscopically characterised by a single damage variable. If the damage is assumed to be isotropic, it has the same value in all directions, and the scale damage variable completely characterises the three-dimensional damage state:

$$
D=\frac{V_{D}}{V}
$$

where $D$ is the scale damage variable, $V_{D}$ is the damaged volume and $V$ is the whole volume of the representative volume element (RVE). The value of the damage variable is in the range of $0 \leqslant D<1$, 

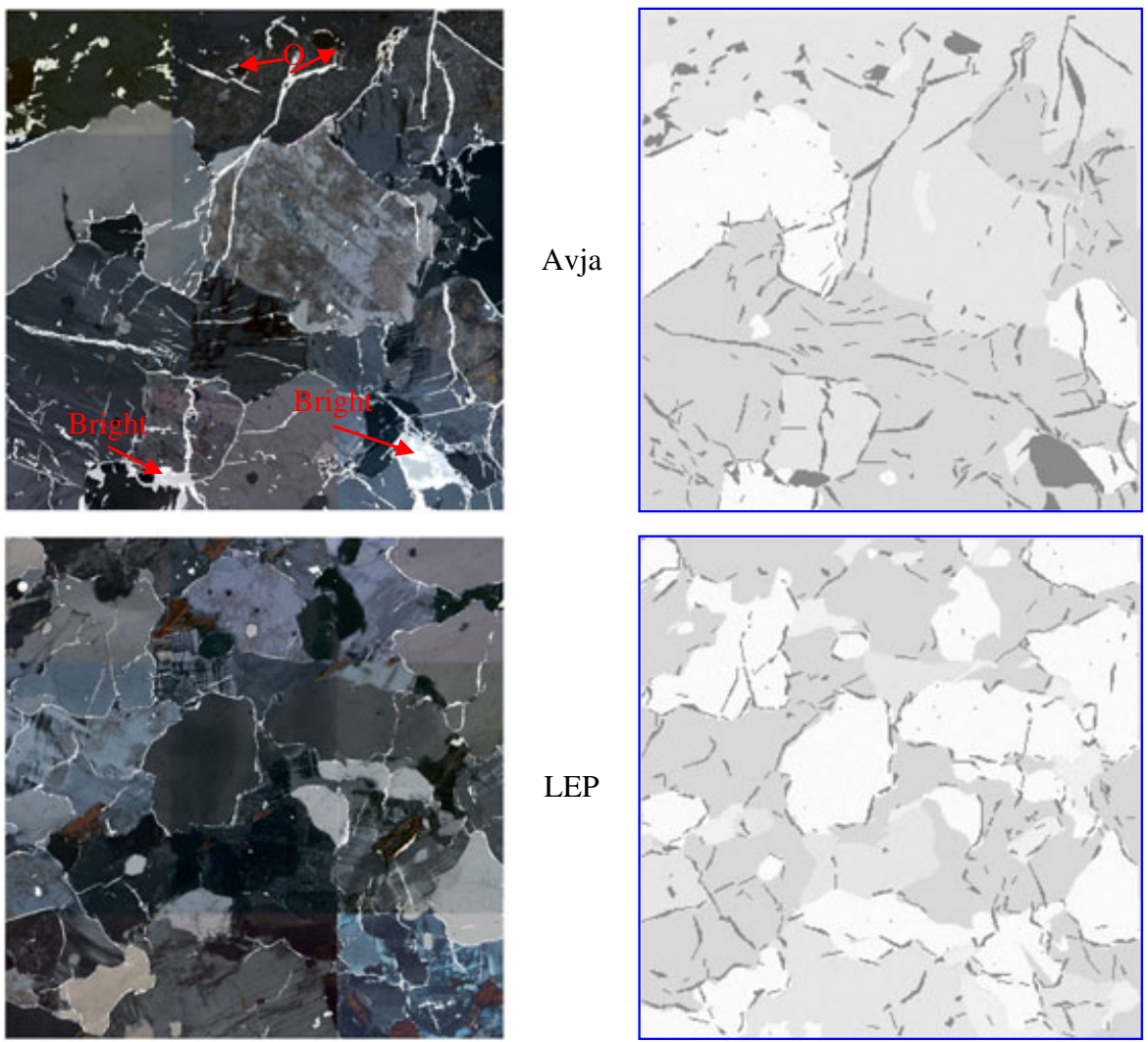

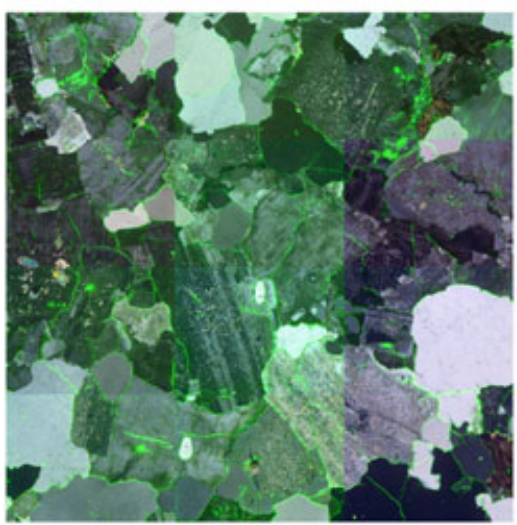

(a) Microstructures obtained from microscopic observations

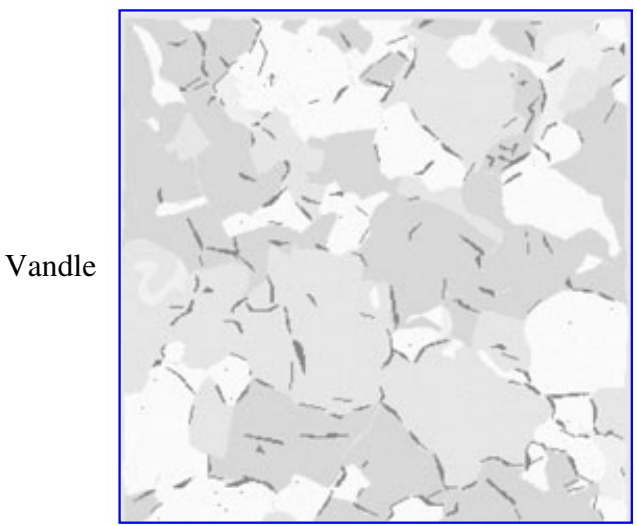

(b) Numerical models built according to the microstructure

Figure 1. Microstructures and numerical models of the representative volume elements (RVE) of the three types of granites called Avja, LEP and Vandle.

where the value of 0 corresponds to undamaged RVE material and the value of 1 to fully broken material. The stress-strain relation for isotropic damage can be expressed as:

$$
\sigma_{i j}=(1-D) C_{i j k l} \varepsilon_{k l}
$$

During the numerical modelling, the RVE is the finite element in the finite element network. At the beginning of loading, the element is considered to be isotropically elastic, and its elastic properties can be defined by the Young's modulus $E_{0}$ and the Poisson's ratio. The stress-strain curve of the element is considered linear elastic until the given damage threshold is attained and is then followed by 
softening (Figure 2). The maximum tensile stress criterion and the Mohr-Coulomb strength criterion are selected as two damage thresholds. In all cases, the tensile stress criterion is preferable.

Under tensile stress, damage occurs when the minor principal strain $\varepsilon_{3}$ in the element reaches its maximum tensile strain, $\varepsilon_{\mathrm{t} 0}$, that is

$$
\varepsilon_{3} \geqslant-\varepsilon_{\mathrm{t} 0}
$$

After the tensile damage occurs, the damage evolution of the mesoscopic element can be expressed as follows:

$$
D=\left\{\begin{array}{cc}
0 & \varepsilon>\varepsilon_{\mathrm{t} 0} \\
1-\frac{\sigma_{\mathrm{tr}}}{E_{0} \varepsilon} & \varepsilon_{\mathrm{t} 0} \geqslant \varepsilon>\varepsilon_{\mathrm{tu}} \\
1 & \varepsilon \leqslant \varepsilon_{\mathrm{tu}}
\end{array}\right.
$$

where $\sigma_{\mathrm{tr}}$ is the residual tensile strength, which is defined as $\sigma_{\mathrm{tr}}=\lambda \sigma_{\mathrm{t}} . \lambda$ is the residual strength coefficient. $\varepsilon_{t 0}$ is the tensile strain at the elastic limit, which is the so-called tensile threshold strain. $\varepsilon_{t u}$ is the ultimate tensile strain of the element, which indicates that the element would be completely damaged when the tensile strain of the element attains this ultimate tensile strain. The ultimate tensile strain is defined as $\varepsilon_{\mathrm{tu}}=\eta \varepsilon_{\mathrm{t} 0}$, where $\eta$ is called the ultimate tensile strain coefficient.

Under compressive stress, damage occurs when the major principle strain $\varepsilon_{1}$ of the element satisfies the compressive threshold strain prescribed by the Mohr-Coulomb strength criterion, that is

$$
\varepsilon_{1} \geqslant \varepsilon_{c 0}=\frac{1}{E_{0}}\left[\sigma_{1}-\frac{(1+\sin \phi)}{(1-\sin \phi)} \sigma_{3}\right]
$$

where $\sigma_{1}$ is the major principal stress, $\sigma_{c}$ is the uniaxial compressive strength (UCS), and $\phi$ is the internal friction angle. After the compressive damage occurs, the damage variable $D$ can be described as follows:

$$
D=\left\{\begin{array}{cc}
0 & \varepsilon<\varepsilon_{\mathrm{c} 0} \\
1-\frac{\sigma_{c r}}{E_{0} \varepsilon} & \varepsilon \geqslant \varepsilon_{\mathrm{c} 0}
\end{array}\right.
$$

where $\sigma_{c r}$ is the residual compressive strength and $\varepsilon_{c 0}$ is the compressive threshold strain.

When the tensile strain of the fractured element reaches the ultimate tensile strain, the element is completely damaged to represent the crack opening. When the compression strain of the element

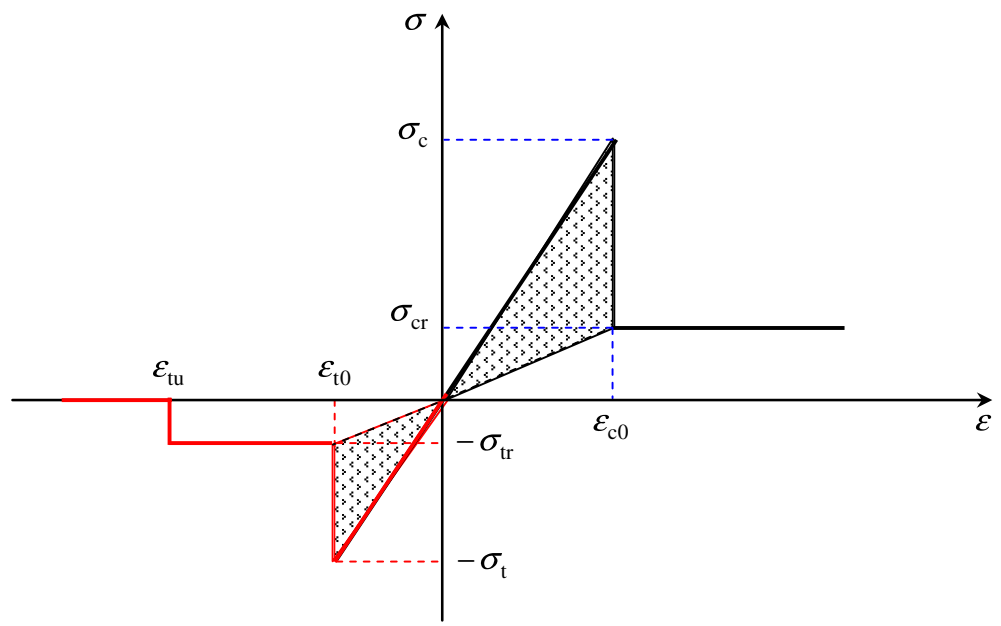

Figure 2. Mesoscopic elemental constitutive relations under uniaxial compressive and tensile stresses. 
reaches the re-compaction strain, the element is re-compacted depending on the lateral pressure to represent the crack close. The RFPA-RT code is introduced in detail in a previous thesis [19]. Moreover, the calibration studies on some typical physical-mechanical and fracture mechanics experiments prove that this model can effectively simulate the non-linearity of the stress-strain response, localization of deformation, strain softening, crack initiation, propagation, interaction and coalescence in heterogeneous rock under a variety of quasi-static loadings [12].

Therefore, during the modelling using the RFPA-RT code, the numerical simulation model is first built for the rock to be investigated. Then the initial boundary conditions are applied on the model, and the elements in the model are brought to the equilibrium state under the initial boundary conditions. After that, a stress disturbance is applied to the numerical model, which may be caused by force loading, displacement loading or stress redistribution. A finite element stress analyser is used to calculate the stress and strain distributions in the finite element network because of the stress disturbance. The calculated stresses are substituted into maximum tensile stress criterion and then the Mohr-Coulomb strength criterion to check whether or not elemental damage occurs. If the strength criterion is not satisfied, the external loading is increased further. Otherwise, the element is damaged and becomes weak according to the rules specified by the mesoscopic elemental mechanical model for elastic damage, which results in a new perturbation. The stress and deformation distributions throughout the model are then adjusted instantaneously after each rupture to reach the equilibrium state. Because of the new stress disturbances, the stress of some elements may satisfy the critical value, and further ruptures are caused. The process is repeated until no failure elements are present. The external load is then increased further. In this way, the system develops a macroscopic fracture.

\section{REALISTIC TEXTURE-BASED MODELLING OF ROCK AGGREGATE BREAKAGE}

In this section, the microscopic observation, image analysis and numerical modelling are integrated together to simulate the rock aggregate breakage: image acquisition, image processing, meshing, computation of stress, strain and displacement, crack initiation, propagation, coalescence and interaction. Two methods are proposed for the realistic texture-based modelling: microstructural modelling and micromechanical modelling. In the microstructural modelling, the numerical model is built on the basis of the RVE of the microstructures of the investigated rock aggregate. In the micromechanical modelling, the numerical model is established according to the statistical analysis of quantitative microstructure results.

\subsection{Microstructural modelling}

An RVE of the rock is firstly observed using the microscopic method described in section 2 to obtain the microstructure of the rock. Then the microstructure of RVE is recorded in the memory of the computer, and image analysis is used to simplify the microstructure, to segment the constituent phases and polygon mineral and crack shapes. During the image analysis, the position, morphology and type of the constituent phases are recorded in a data file. After that, a dynamic data exchange module is developed in the RFPA-RT code to receive the data files from the image analysis, and the numerical model is built according to homogenisation theory in engineering geology. Finally, the RFPA-RT code is used to simulate the breakage properties of the built numerical model.

4.1.1. Construction of numerical models according to rock actual microstructure. Figure 1(a) is an example of the combined polarising and fluorescent image of Avja, LEP and Vandle using the method described in section 2. An image analysis program, Particle2D [20], is used to process the microstructure image, to segment the constituent phases and polygon the mineral and crack shapes. Once the morphological information of the constituent phases has been gained, it is possible to construct the numerical model after specifying the physical-mechanical properties of the major constituent phases, that is quartz, $\mathrm{K}$-feldspar, plagioclase, mica and crack. The physical-mechanical properties of the minerals can be found in the literatures [21, 22], and it is assumed that cracks are filled with weak materials in this study. The physical-mechanical properties of the minerals and weak materials are summarized in Table I. Figure 1(b) depicts the corresponding numerical models to the microstructures of RVEs 
Table I. Physical-mechanical properties of the major constituent phases in Avja, LEP and Vandle.

\begin{tabular}{lccc}
\hline Properties & & & \\
\cline { 1 - 1 } Mineral type & Elastic modulus (GPa)*1 & Compressive strength (MPa)*2 & Poisson ratio \\
\hline K-Feldspar (K) & 69.7 & 1600 & 0.301 \\
Mica (M)*3 & 88.1 & 3000 & 0.248 \\
Quartz (Q) & 95.6 & 5200 & 0.079 \\
Plagioclase (P) & 80.4 & 1600 & 0.300 \\
Crack*4 & 8.52 & 1.43 & 0.300 \\
\hline
\end{tabular}

*1: From Bass (1995).

*2: From Ichikawa et al. (2001).

*3: Mica includes Muscovite, Biotite and Chlorite.

$* 4$ : It is assumed that cracks are filled with weak materials.

shown in Figure 1(a). In Figure 1(b), the same mineral has been marked with the same colour, and the different grey degrees represent the relative size of the elastic modulus of different constituent phases. The brightest grey scale represents quartz and the darkest represents crack filled with weak materials.

The RVE is usually very small, but the specimens of rock in mechanical tests are relatively large in comparison with the RVE. The numerical model corresponding to the specimens in mechanical tests can be constructed according to the RVE of a specimen on the basis of the homogenisation theory in engineering geology. In homogenisation theory, it is usually assumed that a composite material is locally formed by the spatial repetition of very small microstructures, that is microscopic cells, when compared with the overall macroscopic dimensions of the structures of interests. Here, the RVE is the microscopic cell. Thus, the numerical models for mechanical tests are built by the spatial repetition of the microstructure of the RVE. The size of RVEs for the three types of rock in this study is $4 \mathrm{~mm} \times 4 \mathrm{~mm}$, which is determined mainly according to two criteria: (i) the RVE should include all of heterogeneities such as minerals, cracks and pores in that rock type; and (ii) the maximum size of heterogeneities should be relatively small compared with the dimensions of the RVE. However, further works are needed to study the size of the RVE more carefully. In Figure 3, the rock LEP is used as an example to show how numerical models for various numerical tests of LEP can be constructed on the basis of the microstructure, where the size of the element is $0.05 \mathrm{~mm}$. It can be seen that all of the specimens have a characteristic length of $10 \mathrm{~mm}$ because the rock aggregates with this size are used in most of the rock aggregate tests.

4.1.2. Calibration of the microstructural modelling. The numerical model built in section 4.1.1 for the UCS test is loaded to failure using the RFPA-RT code. Figure 4(a) records the failure process of LEP in the UCS test. The corresponding force - displacement curves are plotted in Figure 5. It can be seen that the failures firstly occur in the weak materials filling in the pre-existing cracks, and the tensile failures are the main mechanics. Those failures make the pre-existing cracks open. Then, the continuous loading displacement causes some pre-existing cracks to close again. As the loading displacement increases, some pre-existing cracks are caused to propagate. It is found that most of the crack propagations occur in the minerals of K-feldspar and plagioclase, which form the transgranular cracks. When the quartz mineral is located in front of the crack propagation, the cracks usually propagate following the boundaries of quartz to form the grain boundary cracks, except that the propagating crack meets the pre-existing crack in the quartz mineral. With the loading displacement increasing, the individual cracks coalesce with each other to form long cracks, which correspond to the post-failure region of the force - displacement curve in Figure 5. Finally, the long cracks further propagate to gradually form the failure surfaces, which are the shearing and slipping region in Figure 5. It seems that tensile splitting failures are the main mechanisms to form final failure surfaces. Therefore, the obtained force-loading displacement curve and the observed failure process are consistent with those recorded in literatures [23, 24], which indicate that the proposed microstructural modelling method is reasonable. Figure 4(b) records the fracture patterns of Avja, LEP and Vandle obtained in UCS tests under the same load. The comparisons between the fracture patterns reveal that Vandle has a more zigzag failure surfaces compared with those in Avja and LEP. 

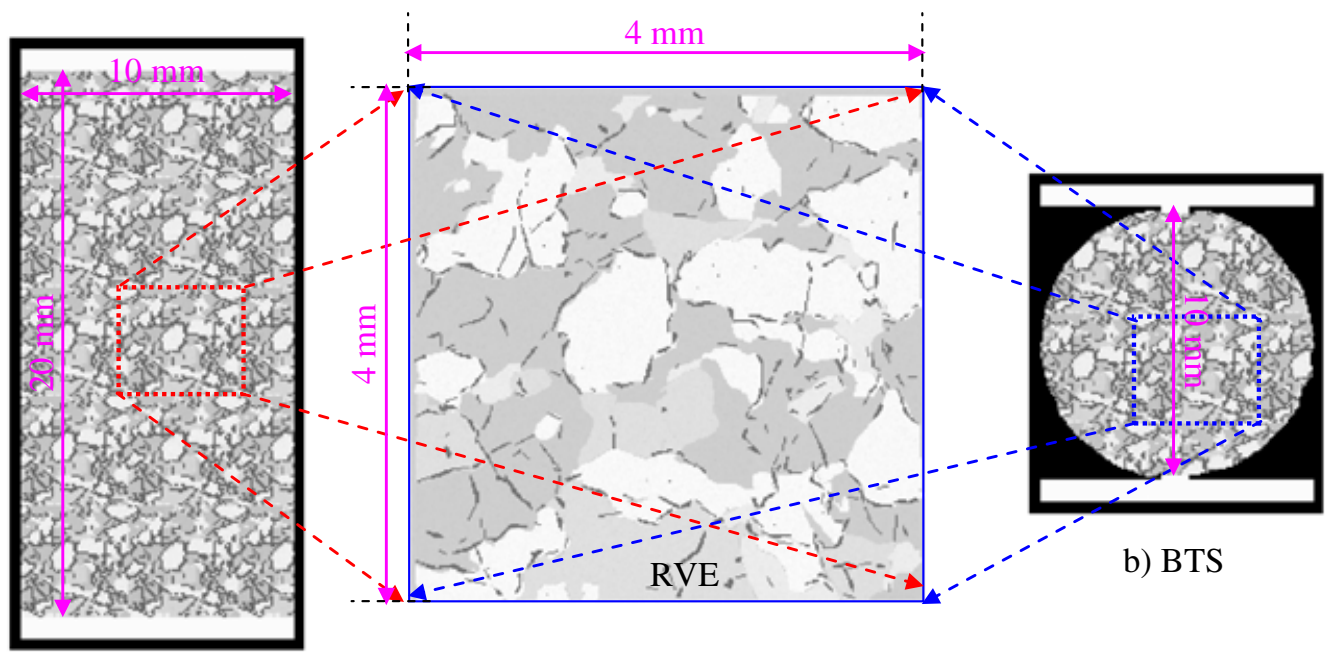

a) UCS

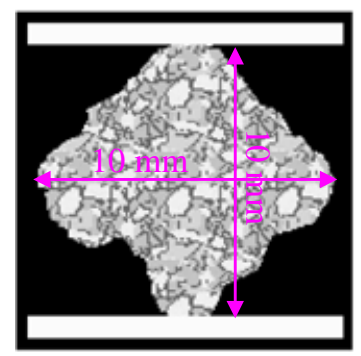

c) Point-to-point

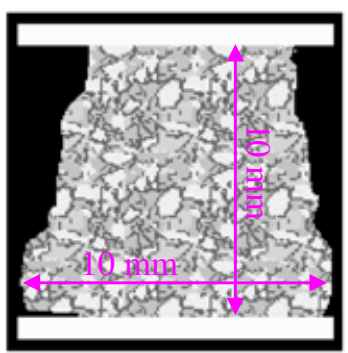

d) Plane-to-plane

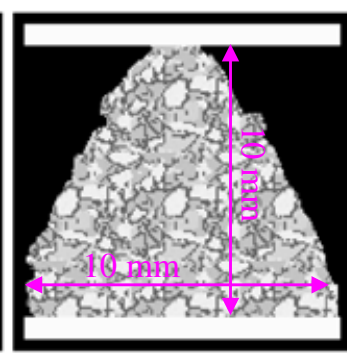

e) Point-to-plane

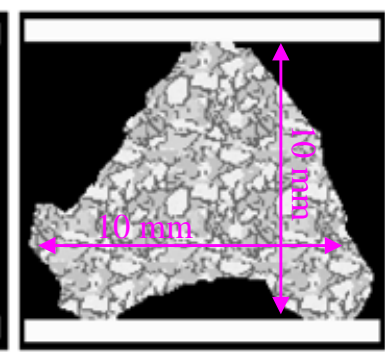

f) Multiple-point

Figure 3. Numerical models built from RVE of LEP for various numerical tests.

On the basis of the peak loads and the linear parts of the force, the displacement curves, the UCS $\sigma_{c}$ and the elastic modulus $E$ can be calculated. On the other hand, the UCS tests are experimentally conducted to obtain the UCS and elastic modulus of Avja, LEP and Vandle. Table II summarizes the modelled UCS and elastic modulus and the comparisons with the experimental results. It can be seen that the numerical results consist with the experimental results quite well with the complex of the problem in the mind, which further reveals that the microstructural modelling is reliable. For the rocks LEP and Vandle, the numerical results are a little bit higher than the experimental results, which are reasonable because in the microstructural modelling, the mineral grain size is relatively bigger compared with the size of the specimen, and there are size effects. In the experiments, one of the specimens of Vandle possesses very low UCS compared with other specimens. The reason is that there are obvious macroscopic defects on that sample. For Avja, the numerical results are a little bit lower than the experimental results, which cannot be explained using size effects. The reason is that the cracks in the microstructure of RVE of Avja may be overestimated. During the image analysis, the other minerals than $\mathrm{K}$-feldspar, plagioclase, quartz and mica are identified as cracks. Maybe, those are the reasons why the numerical results are a little bit lower than the experimental results.

Therefore, on the basis of the qualitative similarity in the comparisons between modelled stressstrain curves and failure processes for Avja, LEP and Vandle, and those recorded in literatures, and the quantitative comparison between the numerical and experimental UCS and elastic modulus, it is reasonable to conclude that the microstructural modelling has a high degree of validity and is reasonably reliable. The method measures that are supposed to measure and the predictions are in fairly good agreement with laboratory results, considering the complexity of the problem.

4.1.3. Microstructural modelling of breakage of single rock aggregate under typical loading conditions. A rock aggregate in services is generally subjected to one of four instant shapes and 


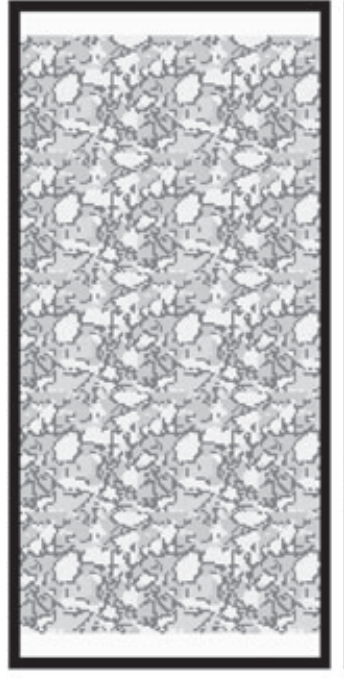

a)

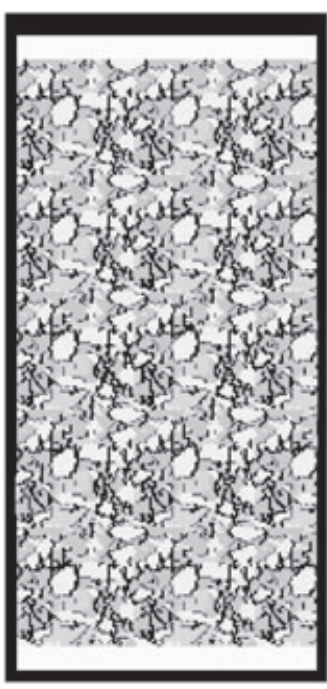

b)

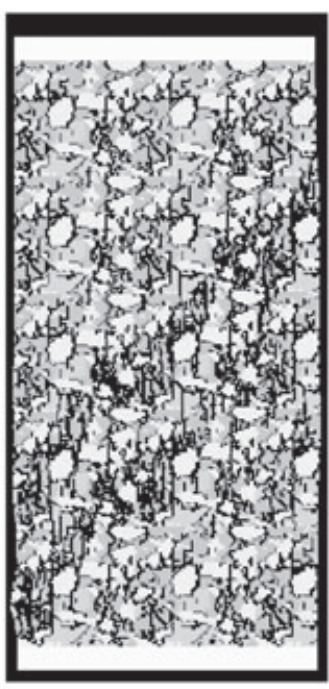

c)

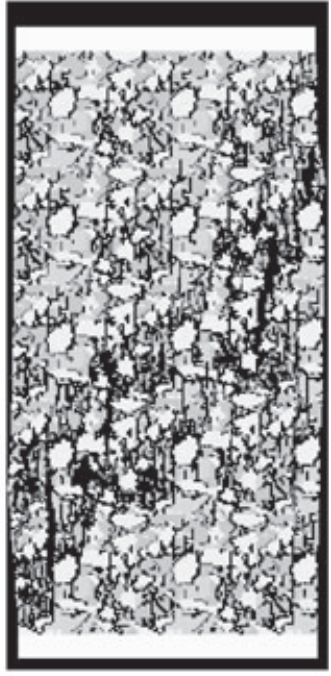

d)

(a) Failure process observed in the UCS test of LEP

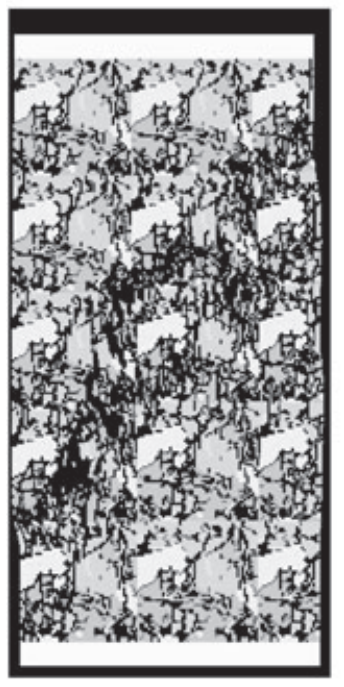

a) Avja

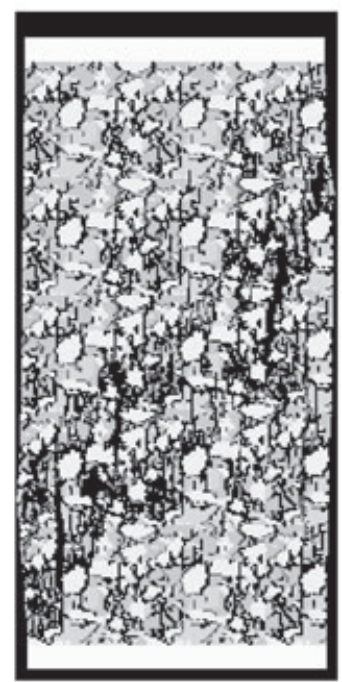

b) LEP

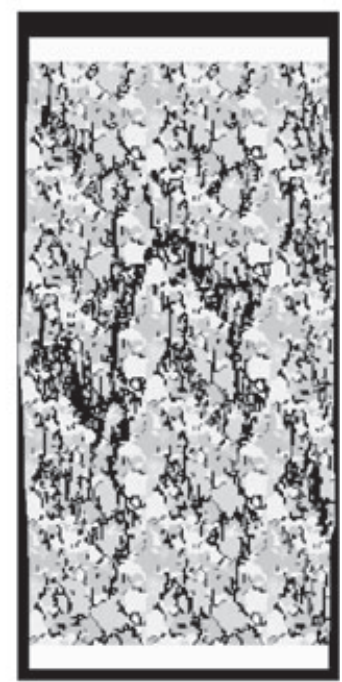

c) Vandle

(b) Fracture patterns

Figure 4. Microstructural modelling of the failure process of Avja, LEP and Vandle in the UCS test.

loading conditions irrespective of whether it is loaded directly by the traffic or by other rock aggregates [25] as follows: (i) point-to-point loading; (ii) plane-to-plane loading; (iii) point-to-plane loading; and (iv) multiple-point loading. Here, the breakage properties of Avja, LEP and Vandle in single rock aggregate breakage tests under the four typical loading conditions are investigated using the microstructural modelling introduced earlier. It can be seen that these four typical loading conditions are more or less related to the loading conditions in Brazilian tests. Therefore, the Brazilian numerical tests are also conducted for the three types of rock because the Brazilian test is well documented than any other single rock aggregate breakage tests. The modelled fracture patterns are depicted in Figure 6 for the three types of rock under various loading conditions.

In Brazilian numerical tests, the pre-existing crack near the central line of the disc propagate radially outward, giving rise to a diametral fracture plane with many small branches and following tortuous 


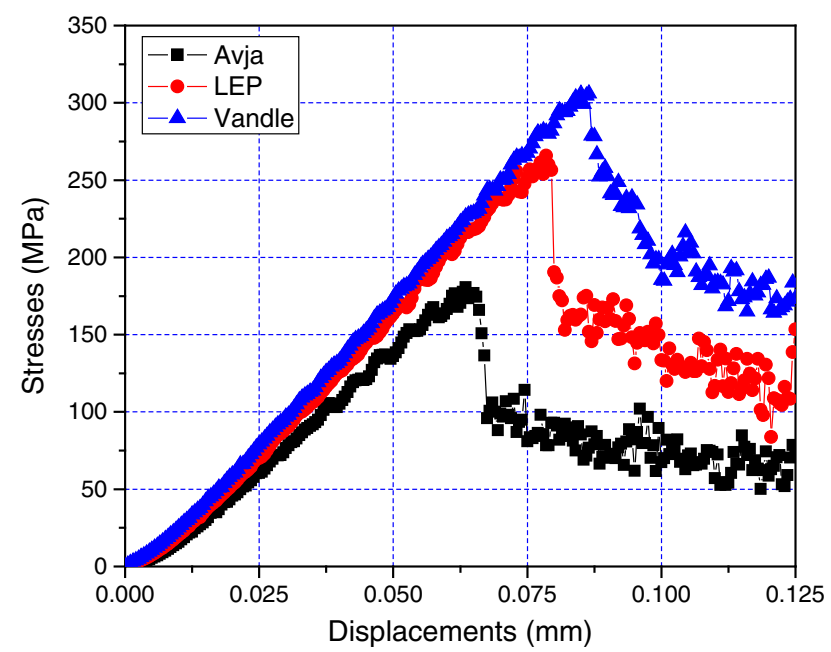

Figure 5. Force (stress) - displacement curves obtained in the microstructural modelling of the UCS test of Avja, LEP and Vandle.

Table II. Calibration of microstructural modelling by comparing the experimental and modelling results obtained in the UCS tests.

\begin{tabular}{|c|c|c|c|c|c|c|c|}
\hline Rock type & & Avja1 & Avja2 & LEP1 & LEP2 & Vandle1 & Vandle2 \\
\hline \multirow[t]{3}{*}{ Elastic modulus (GPa) } & Experiment & 63.18 & 62.43 & 72.35 & 71.10 & 69.97 & 70.56 \\
\hline & & 62.81 & & 71.72 & & 70.26 & \\
\hline & Modelling & 61.01 & & 71.79 & & 73.89 & \\
\hline \multirow[t]{3}{*}{ Strength (MPa) } & Experiment & 193.05 & 196.46 & 219.80 & 208.64 & 240.83 & 173.66 \\
\hline & & 194.76 & & 214.22 & & 207.25 & \\
\hline & Modelling & 180.72 & & 265.85 & & 306.12 & \\
\hline
\end{tabular}

paths. The comparison among the modelled fracture patterns of Avja, LEP and Vandle under the same load and the typical fracture pattern observed in relatively homogeneous rock further indicates that the formed fracture plane depends on the distribution of the minerals and pre-existing cracks, that is the microstructures of rocks.

Under the point-to-point loading condition, the rock aggregate is loaded between two points. Main tensile cracks are created through the piece from one loading point to the other because the tensile strength of rock aggregate is much lower than its compressive strength. For the rock LEP, two main tensile cracks propagate between the two loading points, and the aggregate is broken into three smaller progenies because the strong mineral - quartz - is located along the line connecting the two loading points. Minor cracks cluster around the loading points. In fact, this kind of failure mode is rather similar to that induced in the conventional Brazilian test introduced earlier.

Under the plane-to-plane loading condition, the aggregate is loaded between two approximately parallel planes. At first, a number of tensile cracks are initiated at the irregular corners. Then the tensile cracks propagate to form surface splitting, and the irregular parts of the aggregate are spalled. Finally, in the central portion of the aggregate, shear cracks propagate to form through-going localized faulting, and the remaining aggregates are fragmented into two parts. In fact, after the surface chipping, the aggregate breakage test under plane-to-plane loading conditions is similar to the conventional uniaxial compression test.

Under the point-to-plane loading condition, the aggregate is loaded in a mixture of point-to-point and plane-to-plane loading conditions. The fracture pattern shows an actinomorphic distribution with numerous minor cracks around the vicinity of the upper loading point and a major splitting crack extending till the bottom loading platen. In fact, the point-to-point loading condition is rather similar to the well-known indentation test. There is a local crushing zone around the upper loading points. A few long cracks are propagated out of the local crushing zone to form Hertzian cracks and median cracks. 


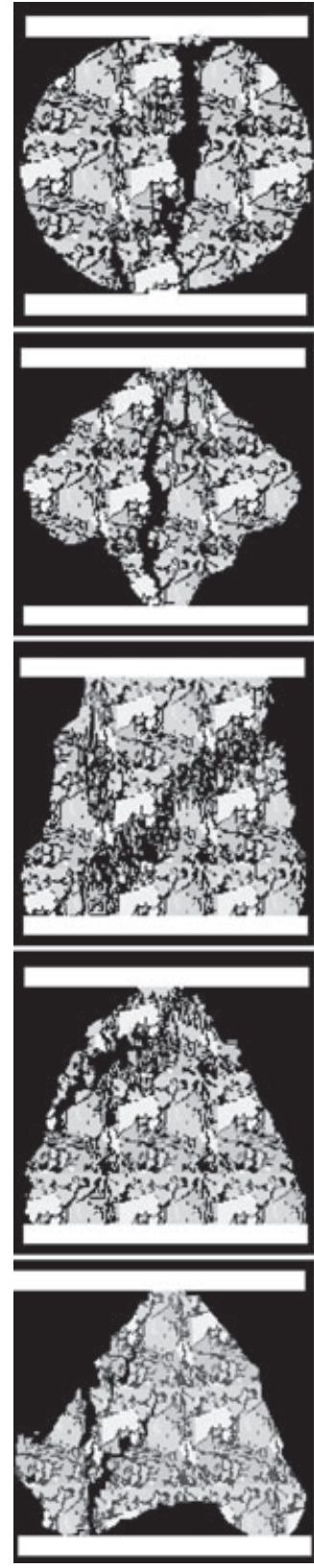

(a) Avja
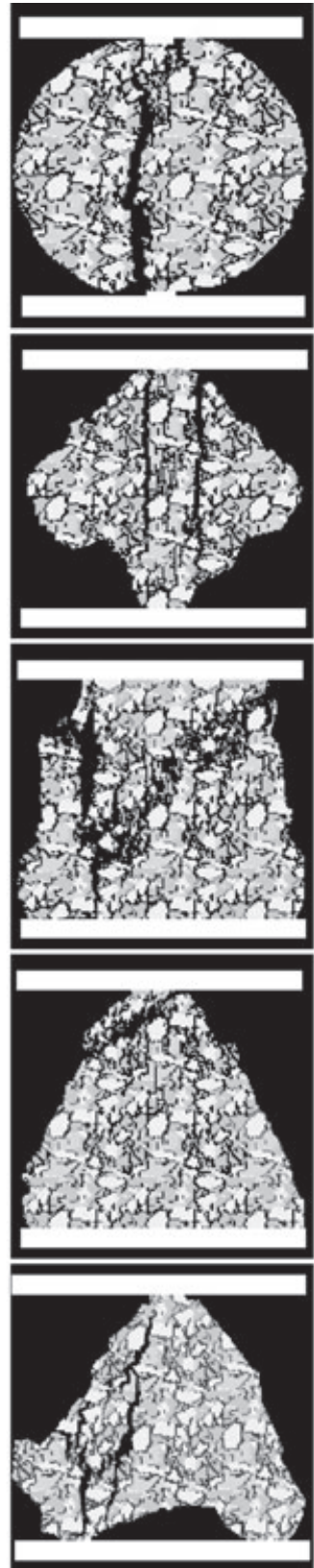

(b) LEP
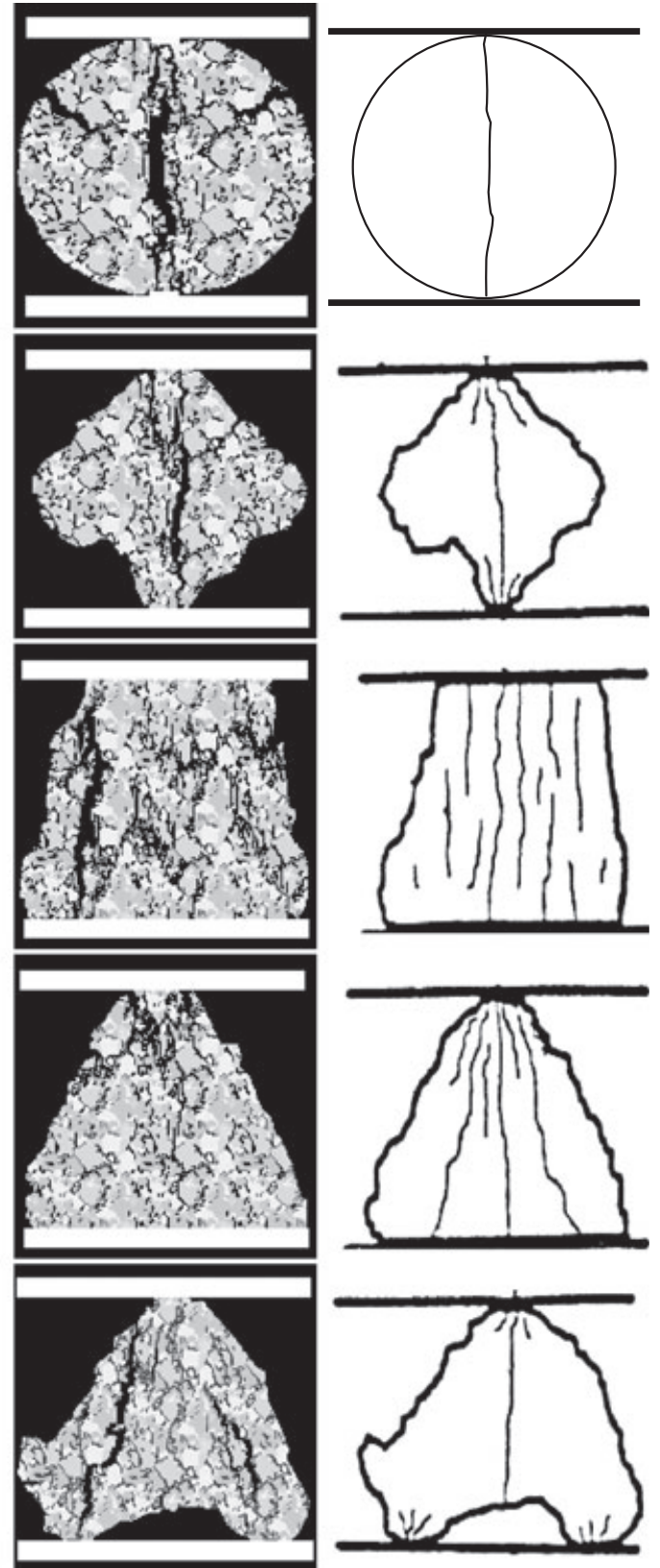

(c) Vandle

(d) Relatively homogeneous rock

Figure 6. Fracture patterns obtained using microstructural modelling in the single aggregate breakage tests of Avja, LEP and Vandle under typical loading conditions and the comparisons with those (Wang et al., 1998) observed in relatively homogeneous rock.

Under the three-point loading conditions, first the major tensile fracture initiates at the middle of the lower surface between the two bottom loading points and propagates upwards. But the fracture propagation then stops. After that, depending on the locations of the loading points, cracks develop around the contact points and propagate along the direction connecting the contact points.

It can be seen from the comparisons between the modelled fracture patterns of Avja, LEP and Vandle that depending on the microstructure, the crack propagation path varies, but the three types of rock have the similar fracture patterns. Quantitative results will be given later in comparison with the calculated results from micromechanical modelling. 


\subsection{Micromechanical modelling}

As introduced in section 1, in previous studies, the microstructures of rock materials have been characterised by using statistical tools. For example, in our RFPA-RT code, the microstructure of rock is described by assigning different material properties to the elements in the numerical model following Weibull distributions. However, it remains unclear to what extent the statistical assumptions on local strength can be justified on rock microstructure and how quantitative microscopy and image analysis results can be used to constrain the statistical model. In this section, the micromechanical modelling will be proposed to construct numerical models on the basis of the quantitative microscopy and image analysis results and then simulate the rock aggregate breakage properties. Again, the three types of rock Avja, LEP and Vandle are used as examples.

4.2.1. Micromechanical model for characterising rock microstructure. In the RFPA-RT code, a heterogeneous material model has been proposed to build the numerical model on the basis of Weibull distribution [19]. According to the heterogeneous material model, it is assumed that each element in the finite element model possesses different physical-mechanical parameters following the Weibull distribution

$$
p(\sigma)=\frac{m}{\sigma_{0}}\left(\frac{\sigma}{\sigma_{0}}\right)^{m} \exp \left[-\left(\frac{\sigma}{\sigma_{0}}\right)^{m}\right]
$$

where $\sigma$ is the elemental parameter, $\sigma_{0}$ is the elemental seed parameter and $m$ is the homogeneous index describing the scatter of the elemental parameter. The integral distribution function of Weibull distribution can be derived as

$$
P(\sigma)=\int_{0}^{\sigma} p(x) d x=1-\exp \left[-\left(\frac{\sigma}{\sigma_{0}}\right)^{m}\right]
$$

In the heterogeneous material model, the assumptions are made that the overall failure is primarily controlled by the weaker elements and that the strength of the weakest element is vanishingly small.

Recently, a number of attempts $[6,16,26]$ have been made to correlate the parameters in the Weibull distribution with the quantitative microstructure results from microscopic observation and image analysis. In the following, the homogeneous index $m$ in the RFPA-RT code will be correlated with the rock microstructure using the method originally proposed by Wong et al. [26], and the seed parameter $\sigma_{0}$ is determined according to the empirical formula proposed by Liu et al. [16].

Firstly, a brief review of the method is presented to show how to determine the homogeneous index $m$. The heterogeneity in a brittle rock is intimately related to the defects statistics, for example micropores and microcracks. When the rock is loaded, one or several of the larger defects in the rock are caused to propagate, as simulated in the microstructural modelling. In a typical defect size distribution observed in heterogeneous rock, the extremal size distribution of defects larger than a certain size $a_{1}$ can be fitted using the distribution function of the Cauchy type

$$
g(a)=\left(\frac{q^{*}}{a}\right)^{z}
$$

where $a$ is the half-length of defects, $q^{*}$ is the extremal parameters and $z$ is defect size distribution shape index or called fractal index. After a series of transformation performed by Wong et al. [26], the probability that the defects in a larger volume, $V$, are larger than $a_{1}$ can be expressed

$$
P=1-\exp \left[-V \int_{a_{1}}^{\infty} g(a) d a\right]=1-\exp \left[-\frac{V}{V_{0}}\left(\frac{a^{\prime}}{a_{1}}\right)^{z-1}\right]
$$

where $V_{0}$ is the elemental volume and $a^{\prime}$ is a length scale defining the lower limit of crack length described by the power law. By applying the fracture mechanics relation $K_{I C}=Y \sigma \sqrt{\pi a}$, the cumulative probability that failure develops at stresses less than $\sigma$ is given by 


$$
P(\sigma)=1-\exp \left[-\frac{V}{V_{0}}\left(\frac{\sqrt{\pi a^{\prime}} \sigma Y}{K_{\mathrm{IC}}}\right)^{2 z-2}\right]
$$

Therefore, by comparing the integral distribution function of Weibull distribution and the equation describing the probability that fracture occurs under a certain stress, the homogeneous index in the heterogeneous material model relates to the rock microstructure, actually, the defect size distribution, by

$$
m=2(z-1)
$$

The seed parameter $\sigma_{0}$ is related to the microstructure by

$$
\sigma_{0}=\left(\frac{V}{V_{0}}\right)^{-\frac{1}{m}} \frac{K_{\mathrm{IC}}}{Y \sqrt{\pi a^{\prime}}}
$$

The main uncertainty in Wong et al.'s [26] procedure lies on the fact that various ways can be used to formulate a 'defect size distribution' in different types of rock. In their studies, the number of cracks, the number of counted cracks per unit scanned, the volume per grain size and the relative frequency have been applied to formulate the defect size distribution. On the basis of those works, further studies should be conducted regarding the determination of the seed parameter in the procedure. In this study, two empirical formulas proposed by Liu et al. [16] are used to determine the seed parameter in the heterogeneous material model

$$
\begin{aligned}
& \frac{\sigma_{c}}{\sigma_{0}}=0.86-0.81 \exp \left(-\frac{m}{10.69}\right) \\
& \frac{E_{c}}{E_{0}}=1.02-0.62 \exp \left(-\frac{m}{2.59}\right)
\end{aligned}
$$

where $\sigma_{\mathrm{c}}$ and $E_{\mathrm{c}}$ are the compressive strength and the elastic modulus, respectively, obtained from mechanical tests; $\sigma_{0}$ and $E_{0}$ are the seed parameters of the compressive strength and the elastic modulus, respectively, in the heterogeneous material model; and $m$ is the homogeneous index.

In the three types of rock Avja, LEP and Vandle under investigation, the main defects in their microstructures are cracks according to the microscopic observations. Figure 7(a) shows the size distributions of cracks observed in Avja, LEP and Vandle using microscope with fluorescent light. As introduced earlier, it is the large defects, that is cracks in this study, that mainly relate to the rock breakage. Thus, the distributions of large cracks (larger than $0.3 \mathrm{~mm}$ ) in Avja, LEP and Vandle are redepicted in Figure 7(b) in terms of the crack frequency. Those distributions are fitted using the distribution functions of the Cauchy type. The following equations are obtained for the three types of rock:

$$
\begin{gathered}
g(a)=0.0083 a^{-2.26506}(\text { Avja }) \\
g(a)=0.00872 a^{-2.36418}(\text { LEP }) \\
g(a)=0.00965 a^{-2.71067} \text { (Vandle) }
\end{gathered}
$$

Thus, the homogeneous index in the heterogeneous material model can be determined for the three types of rock. Besides, the seed parameters can be calculated using the equations introduced earlier on 

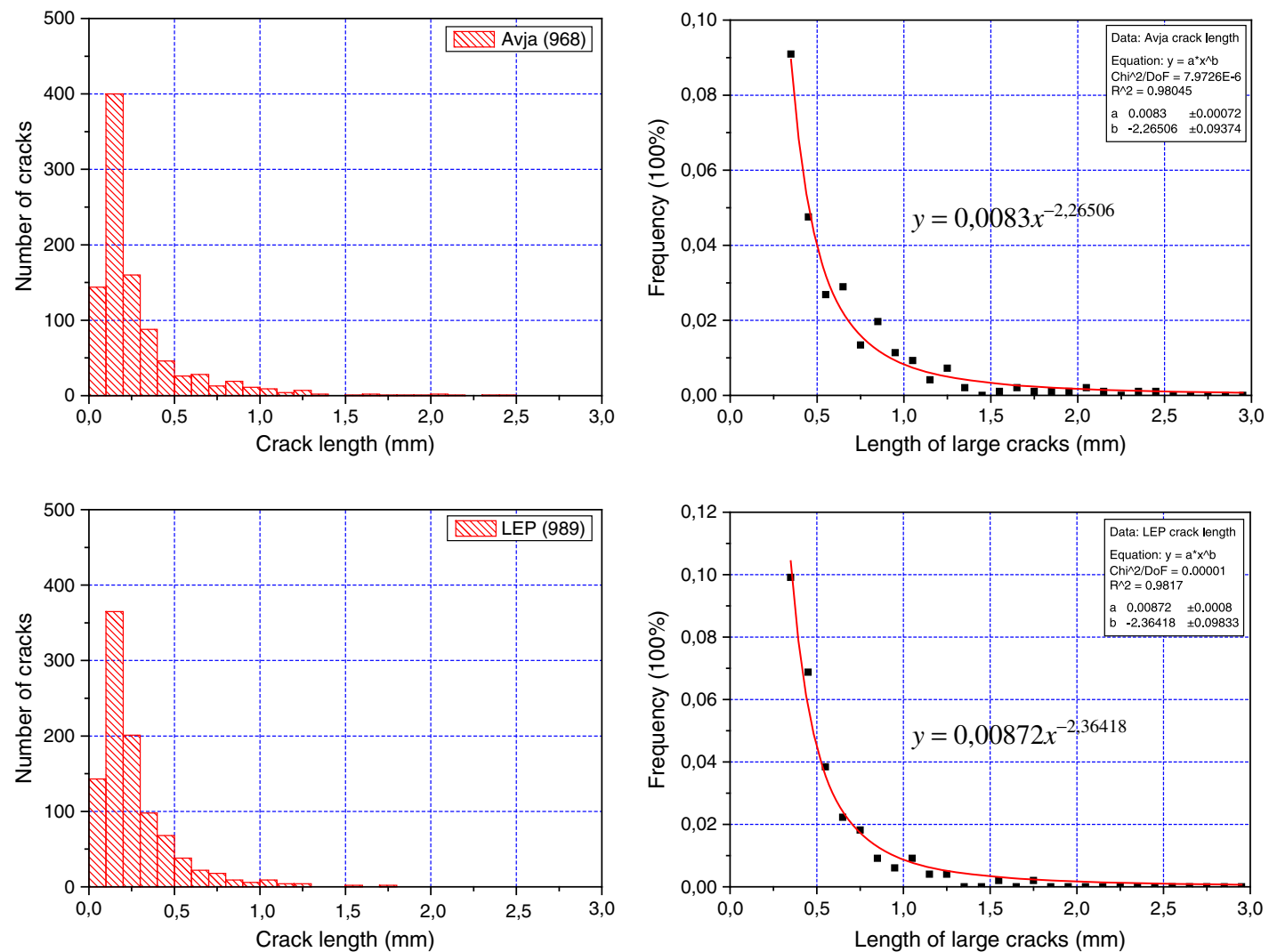

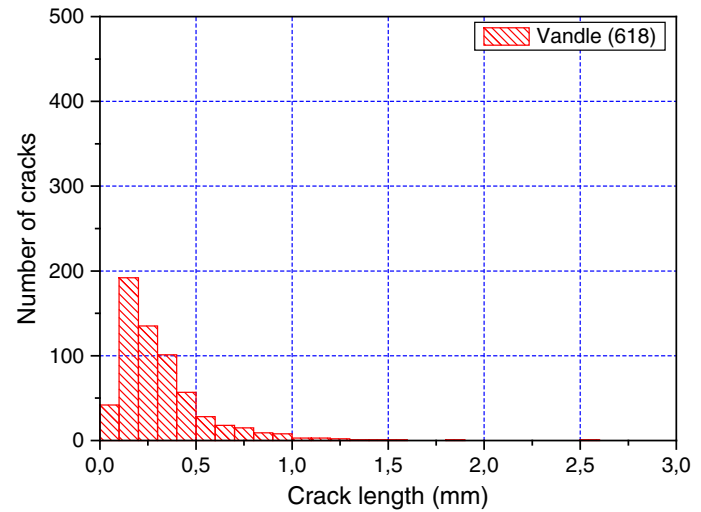

(a) Size distribution of cracks (Number)

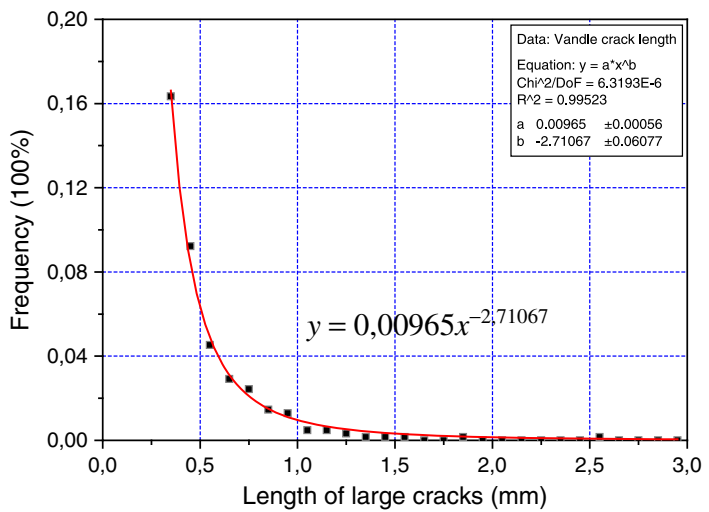

(b) Size distribution of large cracks (Frequency)

Figure 7. Crack size distributions in Avja, LEP and Vandle.

the basis of results from mechanical tests. Table III summarized the calculated results, which will be used as input parameters for the micromechanical modelling of rock aggregate breakage in the next section.

4.2.2. Micromechanical modelling of breakage of single rock aggregate under typical loading conditions. In this section, the single rock aggregate breakage tests in Section 4.1.2 are simulated again using the method of micromechanical modelling, and the obtained results are compared with those obtained using homogenisation modelling.

Figure 8 records the modelled fracture patterns of single rock aggregate in the Brazilian test, and under the point-to-point, plane-to-plane, point-to-plane and multiple-point loading conditions. It can be seen from the comparison between Figures 6 and 8 that the main fracture patterns obtained from the micromechanical modelling are similar to those simulated using the microstructural modelling. 
Table III. Calculated input parameters for the micromechanical modelling.

\begin{tabular}{lccc}
\hline \begin{tabular}{lccc} 
Rock type \\
\cline { 1 - 3 } Parameters
\end{tabular} & Avja & LEP & Vandle \\
\hline$z$ & 2.265 & 2.364 & 2.711 \\
$\left(\mathrm{q}^{*}\right)^{z}$ & 0.0083 & 0.00872 & 0.00965 \\
$m=2 \mathrm{z}-2$ & 2.530 & 2.728 & 3.421 \\
$\mathrm{UCS}(\mathrm{MPa})$ & 194.76 & 214.22 & 207.25 \\
$\mathrm{E}(\mathrm{GPa})$ & 62.809 & 71.722 & 70.265 \\
$\mathrm{BTS}(\mathrm{MPa})$ & 9.45 & 14.9 & 14.75 \\
$v$ & 0.342 & 0.325 & 0.242 \\
$\sigma_{0}(\mathrm{MPa})$ & 874.812 & 914.182 & 757.966 \\
$E_{0}(\mathrm{GPa})$ & 79.430 & 88.769 & 81.819 \\
\hline
\end{tabular}

However, in general, the crack propagation in the microstructural modelling follows more tortuous paths than those in the micromechanical modelling. Moreover, the force - displacement curves from the micromechanical modelling - indicate more brittle behaviours compared with those from the microstructural modelling. These differences are caused by the detail rock microstructures. The microstructure of rock is known to influence its strength and deformation characteristics. Eberhardt et al. [27] showed that the grain size had a significant effect in controlling the behaviour of the cracks once they began to propagate. That is why the crack propagations in microstructural modelling have more tortuous paths than those in micromechanical modelling because the grain size in microstructural modelling in this study is relatively bigger compared with the size of the specimen. The tortuous crack propagations result in more progressive behaviours of the force-loading displacement curves in microstructural modelling.

Table IV compares the modelled aggregate tensile strength, aggregate stiffness and energy utilization ratio of Avja, LEP and Vandle under the various loading conditions using microstructural modelling and micromechanical modelling. Comparing with the results from the microstructural modelling, it is found that most of the results obtained from the micromechanical modelling are smaller. Actually, the results from the micromechanical modelling are closer to the experimental results than those from the microstructural modelling, which can be seen by comparing the modelled aggregate tensile strength and the elastic modulus from the modellings with the experimental tensile strength from Brazilian test (Table V) and elastic modulus from UCS test (Table II). The reasons why the results from microstructural modelling are a little bit far from the experimental results are the influences of the grain size and the specimen size. In microstructural modelling, the grain size is relatively bigger compared with the specimen size, which will control the crack propagation behaviour and then influence the aggregate tensile strength and stiffness. Thus, in order to eliminate the influence of the grain size, as much as possible, the size of the investigated numerical model should be much bigger than the size of the included grain in microstructural modelling. However, on the other hand, the numerical model with a bigger size means more elements should be used, which require the computer with a bigger computer capacity and a faster calculation speed. With the limited computer capacity and calculation speed in the mind, micromechanical modelling is a good method to simulate the breakage properties of rock aggregate with a big size. Therefore, the inter-aggregate breakage will be only modelled using the micromechanical modelling.

4.2.3. Micromechanical modelling of the inter-aggregate breakage in the Dutch Static Compression test. The Dutch Static Compression (DSC) test is initiated in the Netherlands for determining the fragmentation resistance of aggregates [28]. The DSC test is performed by crushing the aggregate with a size fraction $d \sim D$ (where $d \approx 10 \mathrm{~mm}$ and $D=\sqrt{2 d}$ ) in a compression testing machine using a cylindrical steel mould. The test specimen is then sieved on a test sieve with aperture size $d / 2$, and the result of the test, the DSC value, is the amount of the test specimen that passes the test sieve, expressed as a percentage by the mass of the test specimen.

In this section, the micromechanical modelling of the DSC tests is conducted for the three types of rock: Avja, LEP and Vandle. In the micromechanical modelling, the numerical model consists of a 

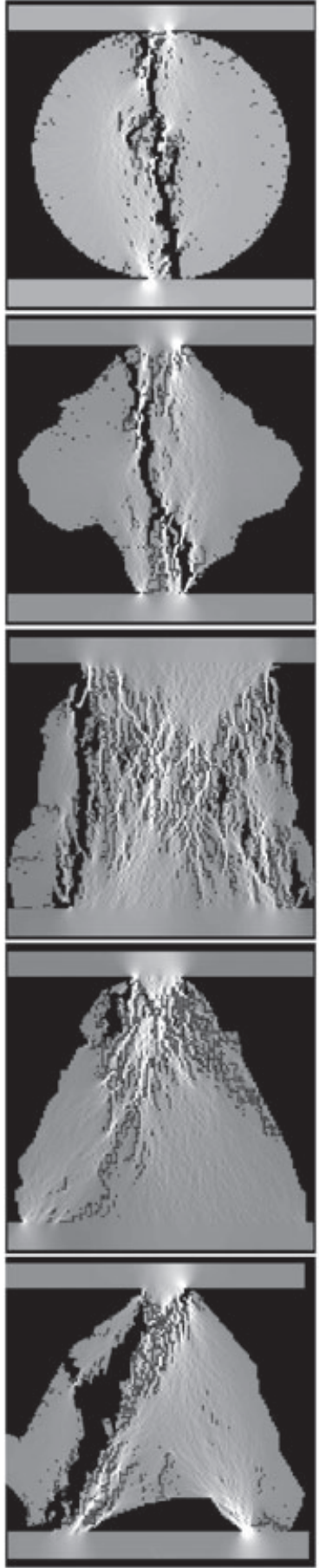

(a) Avja
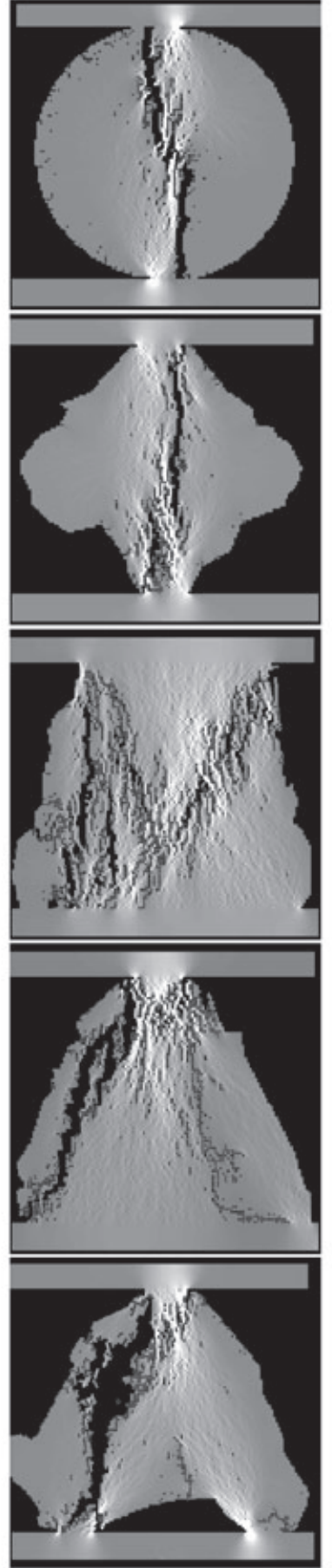

(b) LEP
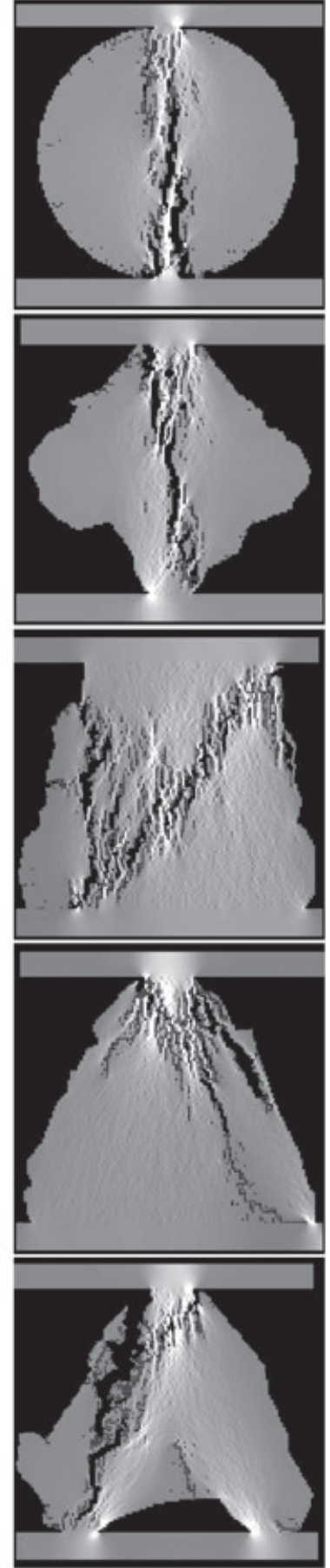

(c) Vandle

Figure 8. Fracture patterns obtained in the micromechanical modelling of the single aggregate breakage tests of Avja, LEP and Vandle under typical loading conditions.

crushing chamber and 15 randomly packed rock aggregates with the diameter of the equivalent circle area between $10-14 \mathrm{~mm}$ where the individual aggregate is subjected to an arbitrary set of contact forces, as shown in Figure 9(a). In the simulation, the axial load is increased by moving the upper loading platen downwards step by step in a displacement control fashion. In the model, the walls of the crushing chamber impose a horizontal constraint against the particles inside, which provides the necessary confined condition for the multiple aggregate breakages. 
Table IV. Comparisons of quantitative results from microstructural modelling and micromechanical modelling.

\begin{tabular}{|c|c|c|c|c|c|c|c|}
\hline \multicolumn{2}{|c|}{ Parameters } & \multicolumn{3}{|c|}{ Microstructural modelling } & \multicolumn{3}{|c|}{ Micromechanical modelling } \\
\hline & ck type & $\begin{array}{c}\text { Tensile strength } \\
\text { (MPa) }\end{array}$ & $\begin{array}{c}\text { Elastic modulus } \\
(\mathrm{GPa})\end{array}$ & $\begin{array}{c}\text { Energy } \\
\text { utilization } \\
\text { ratio }(\%)\end{array}$ & $\begin{array}{c}\text { Tensile strength } \\
\text { (MPa) }\end{array}$ & $\begin{array}{c}\text { Elastic modulus } \\
(\mathrm{GPa})\end{array}$ & $\begin{array}{l}\text { Energy } \\
\text { utilization } \\
\text { ratio }(\%)\end{array}$ \\
\hline \multirow[t]{3}{*}{0} & Ävja030 & 20.36 & 51.76 & 11.99 & 11.25 & 66.746 & 19 \\
\hline & LEP010 & 25.73 & 58.11 & 12.41 & 16.40 & 78.359 & 16.67 \\
\hline & Vändle010 & 38.80 & 63.42 & 13.62 & 17.69 & 72.280 & 18.64 \\
\hline \multirow[t]{3}{*}{1} & Ävja031 & 21.87 & 60.55 & 12.51 & 11.30 & 88.001 & 17.72 \\
\hline & LEP011 & 30.42 & 65.16 & 10.13 & 18.91 & 93.978 & 19.70 \\
\hline & Vändle011 & 41.35 & 74.54 & 10.95 & 18.54 & 87.430 & 19.50 \\
\hline \multirow[t]{3}{*}{2} & Ävja032 & 112.97 & 219.91 & 6.90 & 49.61 & 228.89 & 14.51 \\
\hline & LEP012 & 152.16 & 236.31 & 6.16 & 83.53 & 235.85 & 14.07 \\
\hline & Vändle012 & 159.50 & 227.35 & 5.91 & 75.67 & 175.02 & 14.38 \\
\hline \multirow[t]{3}{*}{3} & Ävja033 & 51.26 & 101.38 & 9.42 & 25.13 & 136.11 & 14.78 \\
\hline & LEP013 & 75.56 & 114.49 & 7.84 & 38.42 & 119.32 & 15.52 \\
\hline & Vändle013 & 88.43 & 123.18 & 7.08 & 38.70 & 139.52 & 14.18 \\
\hline \multirow[t]{3}{*}{4} & Ävja034 & 38.37 & 67.33 & 9.85 & 20.52 & 102.25 & 17.05 \\
\hline & LEP014 & 45.85 & 82.55 & 9.95 & 30.80 & 112.56 & 18.91 \\
\hline & Vändle014 & 79.37 & 85.35 & 11.36 & 30.92 & 102.43 & 16.12 \\
\hline
\end{tabular}

Table V. Tensile strengths of Avja, LEP and Vandle obtained in the laboratory Brazilian tests.

\begin{tabular}{lccc}
\hline Rock type & Avja & LEP & Vandle \\
\hline Test 1 & 9.9 & 14.8 & 13.5 \\
Test 2 & 9.0 & 15.0 & 16.0 \\
Average & 9.5 & 14.9 & 14.8 \\
\hline
\end{tabular}

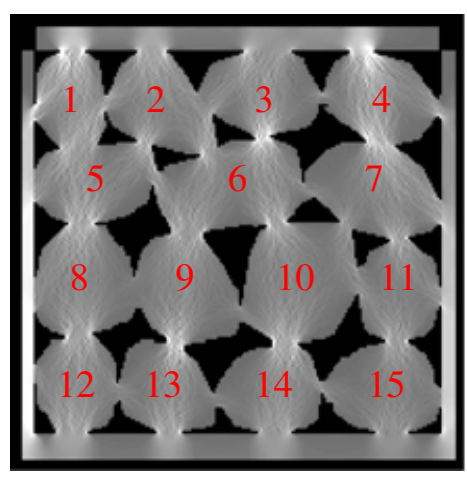

(a) Initial loading stage

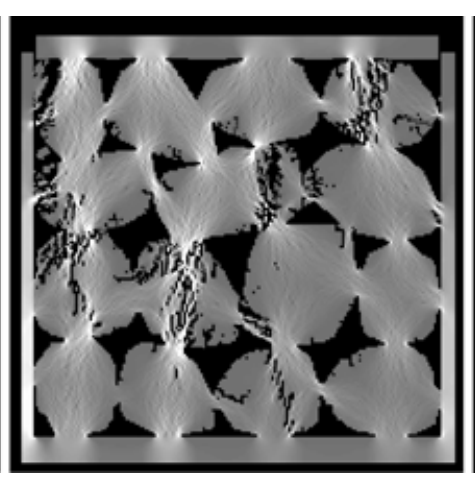

(b) Intermediate fracture process

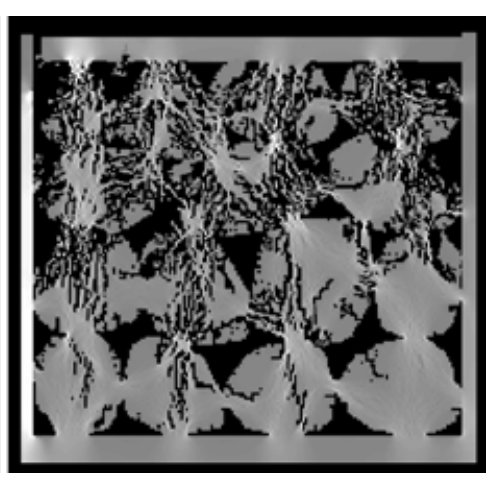

(c) Final fracture pattern

Figure 9. Micromechanical modelling of the inter-aggregate breakage in the DSC test of Vandle.

At the beginning of loading, the splitting macroscopic cracks are initiated and propagate along the lines connecting the two highest stressed contact points consistent with the main loading direction in the rock aggregates loaded under point-to-point loading conditions, for example the aggregate numbers 4, 6, 8, 9 and 14 in Figure 9(b). The tensile cracks are also generated between two stressed contact points, the connecting line of which is not consistent with the main loading direction in the rock aggregates loaded under multiple-point loading conditions, for example the aggregate numbers 8 and 9 in Figure 9(b). As the loading displacement increases, numerous cracks are initiated around 
certain contact points, and those cracks propagate out of the contact points to form actinomorphic distributions around the vicinity of the contact points in the rock aggregate loaded under point-plane loading conditions, for example the aggregate numbers 8 and 9 in Figure 9(c). Finally, the rock aggregates in the crushing chamber loaded under the plane-to-plane loading conditions are crushed into failures, which results in numerous small progenies, for example the aggregate no. 3 in Figure 9(c). Some aggregates still remain intact because of their particular shapes and loading conditions, for example the aggregate no. 15 in Figure 9(c). Therefore, it can be seen that in general, the interaggregate breakage processes in the DSC tests follow the breakage procedure identified in the single aggregate breakage tests, that is the aggregate breaks in the sequence under the point-to-point, multipoint, point-to-plane and plane-to-plane loading conditions. However, in the inter-aggregate breakage process, the breakages of aggregates under the four loading conditions are actually interlaced with each other, and it is difficult to distinguish which aggregate breakages are caused by loads in which loading conditions.

The fracture patterns obtained in the micromechanical modelling of the DSC tests of Avja, LEP and Vandle do not show a big difference. Thus, only the fracture patterns for Vandle are shown in Figure 9. In order to quantify the difference, the fracture patterns of Avja, LEP and Vandle obtained in the DSC numerical tests under different loading levels, that is the loading displacements of $0.15,0.3$, 0.45 and $0.6 \mathrm{~mm}$ are analysed using the image analysis program, Particle2D [20], to calculate the DSC strength. The image analysis is conducted according to the following procedure: (i) processing the image; (ii) segmenting and polygoning the fragment; (iii) modifying the errors manually; and (iv) calculating the fragment size, which is defined as the diameter of the equivalent circle area to the area of the fragment. On the basis of the obtained fragment size distribution, it is possible to calculate the DSC value. In this study, the area of the fragments or the aggregates is used instead of the weight because the density is assumed as the same, and the problem is simplified as a two-dimensional plain strain problem. Similar to the experimental DSC test, the fragment with a size smaller than the half size (i.e. $5 \mathrm{~mm}$ ) of the original aggregate is regarded as passing the sieve. Table VI summarizes the calculated DSC values of Ävja, LEP and Vändle under various loading displacements (Steps). It can be seen that the calculated DSC value of Avja is obviously higher than those of LEP and Vandle, and consequently Avja is easier to fragment. The difference between LEP and Vandle under the various loading conditions is very small: in the initial loading stage (0.15 and 0.3), LEP is easier to fragment but stronger in later stages $(0.45$ and 0.6$)$. This may be caused by the different heterogeneous microstructures. According to the micromechanical model, LEP has a more heterogeneous microstructure than Vandle. During the first stage of the loading process, there are more aggregate breakages in the DSC test of LEP because it has a more heterogeneous microstructure, but its strength and stiffness are similar to those of Vandle. During the final stage of the loading process, a lot of aggregates break simultaneously in the DSC test of Vandle because Vandle has a more homogeneous microstructure than LEP. However, the difference between the DSC strengths of LEP and Vändle under the various loading displacement is very small, which shows that LEP and Vändle have similar breakage properties.

The DSC tests of Avja, LEP and Vandle were also conducted in a laboratory, and the obtained DSC strengths are listed in Table VI. The comparison between the experimental and numerical DSC strengths indicates that the calculated DSC strengths under the loading displacement of $0.3 \mathrm{~mm}$ are close to the experimental results. The consistency between the experimental and the numerical DSC

Table VI. Calculations of the DSC strength in the micromechanical modelling of quasi-DSC tests of Avja, LEP and Vandle under different loading displacements and the comparison with the experimental results.

\begin{tabular}{llllr}
\hline DSC strength $(\%)$ & & Avja & LEP & Vandle \\
\hline Numerical simulations & Level-1 $(0.15 \mathrm{~mm})$ & 32.80 & 24.98 & 19.64 \\
& Level-2 $(0.3 \mathrm{~mm})$ & 43.55 & 39.69 & 34.91 \\
& Level-3 $(0.45 \mathrm{~mm})$ & 65.92 & 58.21 & 57.91 \\
Laboratory tests & Level-4 $(0.6 \mathrm{~mm})$ & 74.38 & 60.23 & 66.31 \\
\hline
\end{tabular}


strengths reveals that the micromechanical modelling proposed in this study may provide a robust tool to evaluate rock aggregate breakage properties.

\section{DISCUSSIONS}

\subsection{Microstructural modelling and micromechanical modelling}

Two kinds of methods, that is microstructural modelling and micromechanical modelling, are proposed in this study to model the rock aggregate breakage properties according to the realistic rock texture. In both methods, the microscopic observation, image analysis and numerical modelling are integrated to investigate the rock aggregate breakage properties. The single rock aggregate breakage tests and the inter-aggregate breakage tests of three types of rock Avja, LEP and Vandle are used as examples.

In the microstructural modelling, the actual microstructure of rock is used in a direct way to model the rock aggregate breakage properties. Thin sections are firstly prepared from the samples of the investigated rock and then observed using the microscopes under polarising lights and fluorescent lights to obtain the rock microstructure. After that, the image analysis is used to simplify the microstructure, to identify the mineral composition, and to segment and polygon mineral grains and cracks to obtain the morphological information. Finally, on the basis of the results from the image analysis, numerical models are built and loaded to investigate the rock aggregate breakage properties.

In the micromechanical modelling, on the basis of the idea that in the heterogeneous brittle material, the defects mainly controls the material breakage properties, the numerical models are built according to a heterogeneous material with a homogeneous index and a series of seed parameters following the Weibull theory. For a specific rock, the homogeneous index is calculated according to the quantitative microscopic observation and image analysis results of the actual rock microstructure. The series of seed parameters are determined on the basis of the results from mechanical tests following the empirical formula. Finally, the numerical models are loaded to investigate the rock aggregate breakage properties.

In the numerical simulations of rock aggregate breakage tests using the microstructural modelling, the results are, in general, a little bit bigger than the experimental results because of the size effects. In the experimental test, specimens with a size of $54 \mathrm{~mm}$ are used, but in the numerical test, specimens with a size of $10 \mathrm{~mm}$ are used. Thus, it is reasonable that the numerical results are a little bigger than the experimental results. Moreover, in the numerical simulation, the grain size is relatively bigger compared with the specimen size, which will influence the crack propagation behaviour during the failure process. It should be noted that for the rock Avja, the numerical results obtained in the uniaxial compressive tests are a little bit smaller than the experimental results, which, we guess, is caused by the numerical model overestimates of the cracks in Avja, because the other minerals than K-feldspar, plagioclase, quartz and mica in Avja are identified as cracks during the image analysis. The results from the single aggregate breakage tests under various loading conditions indicate that Vandle is stronger than LEP, as well as Avja and LEP is stronger than Avja in terms of the aggregate tensile strength and the aggregate stiffness.

In the numerical simulations using the micromechanical modelling, the simulated aggregate tensile strength and aggregate stiffness are very close to the experimental results. The results from single aggregate tests under various loading conditions reveal that Avja is obviously weaker than LEP and Vandle in terms of the aggregate tensile strength and applied work. However, LEP and Vandle are similar to each other. In some loading conditions, Vandle is stronger than LEP, but in other loading conditions, Vandle is weaker than LEP.

The comparisons between the microstructural modelling and the micromechanical modelling indicate that the results from the micromechanical modelling are closer to the experimental results. Moreover, it is found that the results obtained from the single aggregate breakage tests under various loading conditions using the microstructural modelling are higher than those using the micromechanical modelling, which is caused by the influence of the grain size in size effects. In the micromechanical modelling, the grain size is actually the elemental size, which is very small compared with the specimen size. Thus, the grain size has a minor influence. In the microstructural modelling, the mineral grains are represented by various elements, which are relatively bigger 
compared with the specimen size. Therefore, the grain size has a big influence on the aggregate breakage properties. According to Eberhardt et al. [27], the grain size has a significant effect in controlling the crack propagation behaviour. Actually, from the modelled fracture processes, more tortuous crack propagation paths are observed in the microstructural modelling compared with those in the micromechanical modelling.

Moreover, it seems that the microstructural modelling successfully explains why Vandle is stronger than LEP as well as Avja, and LEP is stronger than Avja. The micromechanical modelling also successfully explained why Vandle and LEP are stronger than Avja, but it fails to distinguish Vandle from LEP. The reasons may be that, actually, the differences between Vandle and LEP are too small for the micromechanical modelling to distinguish them or that in micromechanical modelling, the input parameters for Vandle are underestimated because the UCS of one of the samples from mechanical tests is very low compared with that of the others. Actually, it is found that there are obvious macroscopic defects on the sample. Future studies are needed to clarify the subject. Thus, until this moment, it is difficult to conclude that the microstructural modelling is better than the micromechanical modelling. In the authors' opinions, those two methods can be used to supplement each other. The microstructural modelling considers all of the microstructure properties in a direct way. Thus, it can be used to model how the aggregate microstructure properties, such as the mineral composition, grain size, grain shape, grain spatial arrangement, porosity, crack and others influence the aggregate mechanical properties. However, the disadvantages of the microstructural modelling are that: (i) taking the limited computer capacity and calculation speed into consideration, it is difficult for the microstructural modelling to simulate the breakage properties of rock aggregates with bigger sizes. That is why when the inter-aggregate breakages in the DSC tests are modelled, the micromechanical modelling is used; and (ii) in the microstructural modelling, it is time-consuming to conduct the image analysis, that is to simplify the microstructure, to identify the composition, and to segment and polygon the composition phases. Currently, a semi-automatic image analysis is used. In the future, it is expected to be replaced by fully automatic image analysis systems. The micromechanical modelling considers the most important microstructure property, that is the heterogeneity in an indirect way, that is on the basis of the Weibull theory. Besides, the micromechanical modelling also uses the physicalmechanical properties from mechanical tests as input parameters. That is why the results from micromechanical modelling are closer to the experimental results compared with the homogenisation modelling. It can be seen that the micromechanical modelling can seize on the most important features that the aggregate microstructure properties influence the aggregate mechanical properties, but it seems that it is difficult to say at this moment that the micromechanical modelling can distinguish the small differences between the different types of rock. Furthermore, compared with the microstructural modelling, the micromechanical modelling has the advantages in simulating the breakage processes of rock aggregates with a big size, for example, the inter-aggregate breakage process in the DSC test.

\subsection{Relationship between microstructure and breakage properties of rock aggregate}

As described in the introduction, most of the previous studies investigate the relationship between the microstructure and mechanical properties of rock aggregates in two separate processes. On the one hand, the microstructure properties are characterised using optical and scanning electronic microscope. On the other hand, the mechanical properties are obtained through mechanical tests. After that, various kinds of regression models are used to correlate the microstructure properties with the mechanical properties. Thus, these kinds of studies investigate the relationship in an indirect way instead of directly explaining the physical mechanisms. Moreover, most of the previous studies only correlate the mechanical properties of rock aggregate with a single textural property, which results in many contradicted conclusions in literatures because all of the microstructure properties actually work together to affect the mechanical properties of rock aggregates. In this study, the numerical modelling is used as a main tool to directly investigate the relationship between the microstructure and the mechanical properties of rock aggregates, that is from the mechanics point of view. In the microstructural modelling, all of the microstructure properties of rock aggregates influencing their mechanical properties are considered. In the micromechanical modelling, the most important microstructure properties, that is the defects, are incorporated. In the following, the main 
microstructure properties are examined one by one to show how they influence the breakage properties of rock aggregates.

5.2.1. Mineral compositions. Rocks used in this study, that is Avja, LEP and Vandle, are selected because of their similarity in mineral composition but difference in strength so it is not expected to find strong influence from variation in mineral content. It was observed during the simulations, however, that the mineral composition influences the crack propagation mechanisms. When a crack tip meets Kfeldspar or plagioclase, the crack usually propagates across K-feldspar or plagioclase to form transgranular cracks. When the crack tip meets quartz, the crack usually changes its direction and propagates along the boundary of quartz to form grain boundary cracks, except if it coalesces with a pre-existing crack in quartz. Besides, it is found that there are many intragranular cracks in K-feldspar and plagioclase. In quartz, few cracks locate inside the grains, but grain boundary cracks are common. These observations are in agreement with several studies of the formation of microcracks from UCS tests (e.g. [4, 27]). According to Åkesson et al. [4], a moderate alteration of feldspars gives the mineral grains a more ductile behaviour that reduces stress concentration and cracking of the feldspar grains, which may partly explain why Vandle is stronger than Avja and LEP. However, the influence of alteration is not modelled in this study, and future investigations are needed.

5.2.2. Defects (i.e. cracks and pores). The defects, that is pores and cracks, in the rock microstructures have the most important influences on the rock aggregate mechanical properties. In the microstructures of Avja, LEP and Vandle, few pores are observed, and the mainly observed defects are the cracks. The microstructural modelling indicates that it is the propagation, interaction and coalescence of the pre-existing cracks that result in the rock aggregate breakages. The micromechanical modelling reveals that the main mechanical properties of rock aggregates can be explained as long as the cracks in the microstructures of rock aggregates are seized in. Moreover, it is found that the length, number and distribution of cracks together control the rock aggregate mechanical properties. The total amount of cracks is quite similar for Avja, LEP and Vandle, that is 968, 989 and 618, respectively. However, the crack lengths and especially the crack distributions are different. The average crack lengths of Avja, LEP and Vandle are $2.345,2.285$ and $2.02 \mathrm{~mm} / \mathrm{mm}^{2}$, respectively. Moreover, Avja has more than twice of the transgranular cracks compared with the other samples. In mechanical loading, the propagation of the transgranular cracks leads to the breakage of rock aggregate. Thus, the most critical microstructure parameter for the low mechanical properties of Avja is the high abundance of pre-existing transgranular cracks.

5.2.3. Grain size. From the microstructure in Figure 1 obtained using the microscopic observations and image analyses, it can be seen that the mineral grains with large sizes are usually associated with a large number of intragranular and transgranular cracks, especially the K-feldspar and plagioclase minerals. As shown in the modelled aggregate breakage processes, during mechanical loading, these cracks are forced to propagate and coalesce with each other to form the final fracture patterns. Thus, the grain size influences the aggregate mechanical properties indirectly through associated cracks. For the three types of rock Avja, LEP and Vandle, the average grain sizes are 0.75, 0.48 and $0.45 \mathrm{~mm}$, respectively. Thus, Avja has larger grains than LEP and Vandle, which are similar in grain size, which is probably another reason why Avja is weaker than LEP and Vandle.

5.2.4. Grain shape and spatial arrangement. During the microstructural modelling, it is found that for the minerals K-feldspar or plagioclase, grain shape does not have an important influence on the aggregate mechanical properties, because most of the crack propagation starts within K-feldspar and plagioclase to form transgranular cracks. For the mineral quartz, however, the grain shape has an important influence. When the tips of cracks meet quartz, the cracks usually propagate to follow the boundary of quartz to form grain boundary cracks. If the mineral grain has an irregular shape, it consumes more energy for the cracks to propagate further.

The lengths of perimeters, which correspond to an approximate measurement of the grain shape and spatial arrangement, are conducted for the three types of rock: Avja, LEP and Vandle using scanning electronic microscope and image analysis. The calculated perimeter density, which is defined as the perimeter length in a unit area, is $13.0,15.7$ and $16.9 \mathrm{~mm} / \mathrm{mm}^{2}$ for Avja, LEP and Vandle, respectively. An increasing perimeter length has a positive influence on the strength of the rock 
material. Thus, it seems that the measured perimeter explains why Vandle is stronger than LEP, and LEP is stronger than Avja.

\section{CONCLUSIONS}

In this study, microscopic observation, image analysis and numerical modelling are applied together to characterise the relationship between rock microstructure and breakage properties from the mechanics point of view, which is different from that usually used in engineering geology. Two methods, that is microstructural modelling and micromechanical modelling, are proposed. The breakage properties of three types of rock, that is Avja, LEP and Vandle taken from three quarries in Sweden, in single rock aggregate breakage tests and inter-aggregate breakage tests are then modelled using the proposed methods. Throughout this study, it is concluded that:

- The microstructural modelling directly integrates the microscopic observation, image analysis and numerical modelling together and provides a valuable tool to investigate the breakage properties of rock aggregates on the basis of their actual microstructure. However, due to size effects, a model with a large number of elements is needed to accurately model the rock aggregate breakage properties.

- The micromechanical modelling takes the most important microstructure properties, that is defects such as cracks and pores, into considerations and can model the major breakage properties of rock aggregate. But it may fail to distinguish the breakage properties of rock aggregate with similar microstructures.

- In general, the microstructure properties of rock aggregate work together to affect their mechanical properties. It is difficult to correlate a single microstructure property with the mechanical properties of rock aggregates. In particular, for the three types of rock Avja, LEP and Vandle in this study, crack size distribution, grain size and grain perimeter (i.e. grain shape and spatial arrangement) show good correlations with the mechanical properties. The crack length and the grain size negatively affect the mechanical properties of Avja, LEP and Vandle, but the perimeter positively influences the mechanical properties.

- The modelling of rock aggregate breakage properties in both single aggregate breakage tests and the inter-aggregate breakage tests reveals that the aggregate microstructure, aggregate shape and loading conditions influence the breakage process of rock aggregate in service. For the rock aggregate with the same microstructure, the quadratic shape and good packing dramatically improve its mechanical properties. In general, the aggregate is easiest to be fragmented in pointto-point loading condition, and then in the sequence of multiple-point, point-to-pane and planeto-plane loading conditions.

\section{ACKNOWLEDGEMENTS}

The experimental and numerical studies in this investigation were mainly completed at Luleå University of Technology in Sweden, and the analytical work was accomplished at University of Tasmania in Australia. The financial supports from the Geological Survey of Sweden (SGU) and the NARGS and IRGS grants at the University of Tasmania are greatly appreciated. Moreover, the authors would like to thank Lars Persson at SGU for supporting our research work, making valuable comments and suggestion and providing a number of literatures. Besides, we are in debt to Mattias Göransson at SGU for the rock sampling and Lars Jacobsson at Swedish National Testing and Research Institute (SP) for the mechanical tests.

\section{REFERENCES}

1. Hartley A. A review of the geological factors influencing the mechanical properties of road surface aggregates. Quarterly Journal of Engineering Geology and Hydrogeology 1974; 7:69-100.

2. Lundqvist S, Göransson M. Evaluation and interpretation of microscopic parameters vs. mechanical properties of Precambrian rocks from the Stockholm region, Sweden. Proceedings of the 8th Euroseminar Applied to Building Materials. Athens, 2001; 13-20.

3. Åkesson U, Lindqvist JE, Göransson M, Stigh J. Relationship between texture and mechanical properties of granites, central Sweden, by use of image-analysing technique. Bulletin of Engineering Geology and the Environment 2001; 60:277-284. 
4. Åkesson U, Stigh J, Lindqvist JE, Göransson M. The influence of foliation on the fragility of granitic rocks, image analysis and quantitative microscopy. Engineering Geology 2003; 68:23-28.

5. Räisänen M. Relationships between texture and mechanical properties of hybrid rocks from the Jaala-Iitti complex, southeastern Finland. Engineering Geology 2004; 74:197-211.

6. Duarte MT, Liu HY, Kou SQ, Lindqvist PA, Miskovsky K. Microstructural modelling approach applied to rock material. Journal of Materials Engineering and Performance 2005; 14:104-111.

7. Tang CA. Numerical simulation of progressive rock failure and associated seismicity. International Journal of Rock Mechanics and Mining Sciences 1997; 34:249-262.

8. Blair SC, Cook NGW. Analysis of compressive fracture in rock using statistical techniques: Part I. A non-linear rulebased model. International Journal of Rock Mechanics and Mining Sciences 1998; 35:837-848.

9. Tang CA, Liu H, Lee PKK, Tsui Y, Tham LG. Numerical tests on micro-macro relationship of rock failure under uniaxial compression, part I: effect of heterogeneity. International Journal of Rock Mechanics and Mining Sciences 2000; 37:555-569.

10. Fang Z, Harrison JP. Development of a local degradation approach to the modelling of brittle fracture in heterogeneous rocks. International Journal of Rock Mechanics and Mining Sciences 2002; 39:443-457.

11. Liu HY, Kou SQ, Lindqvist PA, Tang CA. Numerical studies on the failure process and associated microseismicity in rock under triaxial compression. Tectonophysics 2004; 384:149-174.

12. Liu HY, Kou SQ, Lindqvist PA, Tang CA. Numerical modelling of the heterogeneous rock fracture process using various test techniques. Rock Mechanics and Rock Engineering 2007; 40:107-144.

13. Mahabadi OK, Grasselli G, Munjiza A. Y-GUI: a graphical user interface and pre-processor for the combined finitediscrete element code, Y2D, incorporating material heterogeneity. Computers \& Geosciences 2010; 36:241-252.

14. Chen S, Yue ZQ, Tham LG. Digital image-based numerical modelling method for prediction of inhomogeneous rock failure. International Journal of Rock Mechanics and Mining Sciences 2004; 41:939-957.

15. Zhu WC, Liu J, Yang TH, Sheng JC, Elsworth D. Effects of local rock heterogeneities on the hydromechanics of fractured rocks using a digital-image-based technique. International Journal of Rock Mechanics and Mining Sciences 2006; 43:1182-1199.

16. Liu HY, Roquete M, Kou SQ, Lindqvist PA. Characterization of rock heterogeneity and numerical verification. Engineering Geology 2004; 72:89-119.

17. Åkesson U. Microstructures in granites and marbles in relation to their durability as a construction material. Ph.D. Thesis, Göteborg University, 2004.

18. Horii H, Nemat-Nasser S. Brittle failure in compression: splitting, faulting and brittle-ductile transition. Philosophical Transactions of the Royal Society of London, Series A: Mathematical, Physical and Engineering Sciences 1986; 319:337-374.

19. Liu HY. Numerical modelling of rock fragmentation process by mechanical tools. Ph.D. Thesis: 32D, Lulea University of Technology, 2004.

20. Wang WX. Binary image segmentation of aggregates based on polygonal approximation and classification of concavities. Pattern Recognition 1998; 31:1503-1524.

21. Bass DJ. Elasticity of minerals, glasses and melts. In Mineral Physics and Crystallography (Vol. 2), Ahrens TJ (ed.). AGU: Washington, 1995.

22. Ichikawa Y, Kawamura K, Uesugi K, Seo YS, Fuji N. Micro- and macrobehaviour of granitic rock: observations and viscoelastic homogenisation analysis. Computer Methods in Applied Mechanics and Engineering 2001; 191:47-72.

23. Wawersik WR, Fairhurst C. A study of brittle rock failure in laboratory compression experiments. International Journal of Rock Mechanics and Mining Sciences 1970; 7:561-575.

24. Lockner DA, Byerlee JD, Kuksenko V, Ponomarev A, Sidorin A. Quasi-static fault growth and shear fracture energy in granite. Nature 1991; 350:39-42.

25. Wang Y, Forssberg E, Klymowsky R. Fine comminution of limestone by roller press-stirred ball milling. Aufbereitungs-Technik-Mineral Processing 1998; 39:267-278.

26. Wong TF, Wong RHC, Chau KT, Tang CA. Microcrack statistics, Weibull distribution and micromechanical modelling of compressive failure in rock. Mechanics of Materials 2006; 38:644-681.

27. Eberhardt E, Stimpson B, Stead D. Effects of grain size on the initiation and propagation thresholds of stress-induced brittle fractures. Rock Mechanics and Rock Engineering 1999; 32:81-99.

28. Ballmann P, Collins R, Elshout JP, Mishellany A, Sym R. Determination of mechanical strength by a compression test: result of the 1995/6 crossing-testing experiment. Technical Report, Testing of industrial products aggregates for construction, 1997. 